\title{
An improved conflicting-evidence combination method based on the redistribution of the basic probability assignment
}

\author{
Zezheng Yan ${ }^{1,2} \cdot$ Hanping Zhao ${ }^{1,2} \cdot$ Xiaowen Mei ${ }^{1,2}$
}

Accepted: 30 March 2021 / Published online: 26 July 2021

(C) The Author(s) 2021

\begin{abstract}
Dempster-Shafer evidence theory is widely applied in various fields related to information fusion. However, the results are counterintuitive when highly conflicting evidence is fused with Dempster's rule of combination. Many improved combination methods have been developed to address conflicting evidence. Nevertheless, all of these approaches have inherent flaws. To solve the existing counterintuitive problem more effectively and less conservatively, an improved combination method for conflicting evidence based on the redistribution of the basic probability assignment is proposed. First, the conflict intensity and the unreliability of the evidence are calculated based on the consistency degree, conflict degree and similarity coefficient among the evidence. Second, the redistribution equation of the basic probability assignment is constructed based on the unreliability and conflict intensity, which realizes the redistribution of the basic probability assignment. Third, to avoid excessive redistribution of the basic probability assignment, the precision degree of the evidence obtained by information entropy is used as the correction factor to modify the basic probability assignment for the second time. Finally, Dempster's rule of combination is used to fuse the modified basic probability assignment. Several different types of examples and actual data sets are given to illustrate the effectiveness and potential of the proposed method. Furthermore, the comparative analysis reveals the proposed method to be better at obtaining the right results than other related methods.
\end{abstract}

Keywords Dempster-Shafer theory $\cdot$ Basic probability assignment $\cdot$ Conflicting evidence $\cdot$ Evidence fusion

\section{Introduction}

With the emergence of various big data platforms, it is becoming easier to access multiple sources of information describing the same research object. However, there is a large amount of conflicting or even distorted information. Therefore, the main challenge is how to fuse these information sources while eliminating interference and preserving the truth.

As an important method for modelling and processing uncertain information fusion [1, 2], Dempster-Shafer (D-S) evidence theory is an effective tool to fuse information from

Hanping Zhao

zhaohanping@bnu.edu.cn

1 Key Laboratory of Environmental Change and Natural Disaster, MOE, Faculty of Geographical Science, Beijing Normal University, Beijing, China

2 Academy of Disaster Reduction and Emergency Management, Ministry of Emergency Management \& Ministry of Education, Faculty of Geographical Science, Beijing Normal University, Beijing, China different sources [3-5], and it can be applied to situations of uncertainty without prior information, which is required for Bayesian theory $[3,6]$. Therefore, it has attracted considerable attention from many scholars and has been widely applied in many fields, such as risk and reliability analysis [7-9], decision making $[10,11]$, fault diagnosis [12-14], pattern recognition $[15,16]$.

However, Zadeh [17] presented the famous "Zadeh's Paradox", which challenges D-S theory. The paradox shows that counterintuitive results obtain when fusing highly conflicting evidence by using Dempster's rule of combination. To address this issue, hundreds of methods have been developed [18-22], and they can be divided into three main categories: (1) modifying Dempster's rule of combination; (2) preprocessing the bodies of evidence; and (3) modifying the closed-world assumption.

Some researchers hold the view that the counterintuitive results are due to Dempster's rule of combination. Therefore, they have proposed various alternative combination rules to replace Dempster's rule of combination. These combination rules mainly focus on how to redistribute conflicting information [23]. The main alternative combination 
rules are Yager's combination rule [24], which assigns conflicting mass assignments to the empty set; Dubois and Prade's disjunctive combination rule [25], which assigns conflicting mass assignments to the union of conflict focal elements; Lefèvre's combination rule [26], which assigns conflicting mass assignments to each focal element based on weighting factors; and a combination rule for the assignment of local conflicts [27], which subdivides global conflicts into local conflicts and then assigns them to the focal elements involved in the conflict.

Some scholars think that the counterintuitive results are due to unreliable evidence rather than Dempster's rule of combination and that the bodies of evidence should be revised before combination [28]. There are two ways to modify the bodies of evidence in practical applications. (1) The first is the weighted average of the bodies of evidence, as in Murphy's simple average of the bodies of evidence [29]. However, Murphy treats all the evidence with the same weight and does not take into account the relationships and difference among bodies of evidence, but not all evidence to be combined has equal significance in real applications. To better determine the weight of each piece of evidence, a series of methods have been published [3, 5, 30-33]. The main difference between these methods is the way in which the weight of evidence is obtained, such as Deng et al.'s weight of evidence based on the evidence distance [30] and Yuan et al.'s entropybased weight [33]. (2) The second is discounting the bodies of evidence. The discounting approach is based on the idea that conflicts are generated by disturbed sources of information. As a result, information from the disturbed sources needs to be treated by discounting factors before combination [4]. The discounting approach was first developed by Shafer [34]. The key is to obtain the discounting factor. Since Shafer's book, many methods for obtaining the discounting factor have been developed. Yang et al. discounted unreliable evidence using the degree of disagreement among bodies of evidence [35]. Schubert dealt with conflicting evidence based on the degree of falsity [36]. Yu et al. proposed a new supporting probability distance to discount conflicting evidence [31].

D-S theory assumes that the frame of discernment is the close world. However, some researchers believe that it is often difficult to determine the closed-world frame of discernment because of the limitations in the scopes of knowledge, there may exist some unknown things, which means the frame is in the open world [37]. When the object of the study is not within the closed-world frame of discernment, it is unreasonable or even wrong to assign the basic probability assignment to each subset in the close world based on different bodies of evidence, which will lead to counterintuitive results. Smets [38] was the first to question the closed-world assumption and put forward the open-world assumption. He proposed the transferable belief model, which assigns conflicts to an unknown new proposition. Subsequently, some scholars have developed combination methods based on open-world assumptions, such as Tang et al.'s method [39], Sun and Deng's method [40], and Wen et al.'s method [1].

These three types of methodologies have played an important role in overcoming the counterintuitive results caused by highly conflicting evidence. However, each methodology has its own limitations. D-S evidence theory possesses several interesting mathematical properties, such as commutativity and associativity [10]. Yager's combination rule, Dubois and Prade's disjunctive combination rule, and Lefèvre's combination rule and other methods of modifying the combination rule not only destroy the mathematical properties but also lose the most important polarizability of Dempster's rule of combination [41]. Moreover, these methods have no effect if the counterintuitive results are caused by sensor failure [3, 30, 42]. Although the combination methods of the weighted average, such as Murphy's and Deng's method, do not destroy the mathematical properties of Dempster's rule of combination, the approaches lose the information of the original evidence and sacrifice the independence of each piece of evidence because the weighted evidence replaces the original $n$ pieces of evidence and fuses itself $n-1$ times with Dempster's rule of combination. Regarding the combination methods of discounting the bodies of evidence, if the discount factor is not reasonable, the ambiguity of the original evidence will increase, which decreases the accuracy of the fusion results. The open-world assumption changes the closure of D-S theory. If the frame of discernment is known, this method is not applicable to conflicting evidence. More importantly, these methods do not work in some cases. To overcome the shortcomings of the existing methods, this research was carried out by the authors.

The sources providing information are not in a stable environment and are always interfered with by the natural environment, human factors, and the performance of the instrument and equipment. In addition, the models that generate the basic probability assignments based on these sources are subject to certain errors. The causes mentioned above may lead to unreasonable or even incorrect basic probability assignments. The unreasonable basic probability assignment is the direct cause of counterintuitive results by fusing the conflicting evidence. Therefore, ensuring the validity and reliability of the basic probability assignment is the basis for fusing the conflicting evidence.

Based on the above analysis, an improved combination method for conflicting evidence based on the redistribution of the basic probability assignment is proposed. First, the redistribution equation of the basic probability assignment is constructed based on four parameters: the consistency degree and conflict intensity among bodies of evidence, the unreliability of the evidence, and the adjusted coefficient. Second, to avoid excessive redistribution of the basic probability assignment, the precision degree obtained by information entropy is 
used as the correction factor to modify the basic probability assignment for the second time. Ultimately, the modified basic probability assignment is fused by Dempster's rule of combination. By comparison with other methods, several different types of examples and actual data sets are illustrated to demonstrate the rationality and effectiveness of the proposed method. The proposed method not only retains the mathematical properties of D-S theory but also overcomes the disadvantages of the weighted average and the discounting method, which compensates for the shortcomings of related methods. Furthermore, the proposed method is able to deal with cases that cannot be solved by other methods, which expands the application of D-S theory.

The paper is organized as follows. Section 2 briefly introduces the preliminaries of the paper. Section 3 proposes indicators for evaluating the improvement methods. In section 4, an improved combination method for conflicting evidence based on the redistribution of the basic probability assignment is proposed. Section 5 illustrates examples to show the effectiveness of the proposed method. In section 6 , various fusion methods are discussed. Finally, a brief conclusion is drawn in section 7 .

\section{Preliminaries}

\subsection{The basic concepts of Dempster-Shafer theory}

D-S theory, proposed by Dempster (1967) and improved by Shafer (1976) [43], is a flexible and effective tool to deal with multisource information without prior information [3, 22]. In this section, we list several commonly used concepts in D-S evidence.

Definition 2.1 (Frame of discernment).

Let $\Theta=\left\{\theta_{1}, \theta_{2}, \cdots, \theta_{n}\right\}$ be a finite nonempty set of mutually exclusive and collectively exhaustive elements, called a frame of discernment. The power sets of $\Theta$ is $2^{\Theta}$, indicated as:

$$
\begin{gathered}
2^{\Theta}=\left\{\phi,\left\{\theta_{1}\right\}, \cdots,\left\{\theta_{n}\right\},\left\{\theta_{1}, \theta_{2}\right\}, \cdots,\right. \\
\left.\left\{\theta_{1}, \theta_{2}, \cdots \theta_{i}\right\}, \cdots, \Theta\right\}
\end{gathered}
$$

where $\phi$ is an empty set. If $A \in 2^{\Theta}, A$ is called a proposition.

Definition 2.2 (Basic Probability Assignment).

For a frame of discernment $\Theta, m(A)$ is a function that maps $A$ to $[0,1]$, formally denoted by $m: 2^{\Theta} \rightarrow[0,1]$, which satisfies the following conditions:

$m(\varnothing)=0 \quad$ and $\quad \sum_{A \in 2^{\ominus}} m(A)=1$

where $m(A)$ is a basic probability assignment (BPA), also called a mass function, which represents the support degree for proposition $A ; m(\varnothing)$ denotes BPA of empty set and is assigned 0 , and if $m(A)>0$, then $A$ is called a focal element. When a piece of evidence is given, the support degree ranging from 0 to 1 is assigned to each possible proposition or combination. The sum of the BPAs corresponding to each piece of evidence is 1 .

Definition 2.3 (Belief function and Plausibility function).

The belief function and plausibility function on $2^{\Theta}$ are defined as follows:

$\operatorname{Bel}(A)=\sum_{B \subseteq A} m(B)$

$P l(A)=\sum_{A \cap B \neq \phi} m(B)$

where $\operatorname{Bel}(A)$ is the belief function, which shows the total support degree for proposition $A ; P l(A)$ is the plausibility function, which represents the maximum volume of support for proposition $A . \operatorname{Bel}(A)$ and $P l(A)$ separately represent the lower and upper limit functions of support for proposition $A$. Therefore, these two functions can be used to represent the uncertainty interval for proposition $A$, which is denoted by $[\operatorname{Bel}(A), P l(A)]$.

Definition 2.4 (Dempster's rule of combination)

Let $m_{1}$ and $m_{2}$, based on the same frame of discernment $\Theta$, be two BPAs provided by two pieces of evidence from independent sources. Dempster's rule of combination is denoted by $m=m_{1} \oplus m_{2}$, which is defined as follows:

$\left\{\begin{array}{c}m(\varnothing)=0 \\ m(A)=\frac{1}{1-k} \sum_{A_{i \cap} A_{j}=A} m_{1}\left(A_{i}\right) m_{2}\left(A_{j}\right)\end{array}\right.$

$k=\sum_{A_{i} \cap A_{j}=\varnothing} m_{1}\left(A_{i}\right) m_{2}\left(A_{j}\right)$,

where $k$ is the conflict coefficient that measures the conflict degree between pieces of evidence; $1 /(1-k)$ is the normalized coefficient that avoids assigning a nonzero probability to the empty set $\phi$ in the combination. The combination rule can be extended directly $[32,44]$, which is denoted by $m=m_{1} \oplus$ $m_{2} \oplus \cdots m_{q}(q$ is the number of pieces of evidence). Note that Dempster's rule of combination is not applicable for fusing multiple pieces of evidence when $\mathrm{k}$ is close to or equals 1 .

\subsection{Types of high conflict}

D-S theory can deal well with general conflicting evidence [5]. However, counterintuitive results were obtained when fusing highly conflicting evidence, which is the primary reason for the criticism of D-S theory. There are four common types of high-conflict evidence fusion as follows [45]:

\section{(1) "Total Trust" Conflict}

"Total Trust" conflict is related to the famous "Zadeh's Paradox". In a multisensor system, we assume that the frame 
of discernment is $\Theta=\{A, B, C\}$ and that there are two bodies of evidence.

$$
\begin{array}{llll}
E_{1}: & m_{1}(A)=0.99 & m_{1}(B)=0.01 & m_{1}(C)=0.00 \\
E_{2}: & m_{2}(A)=0.00 & m_{2}(B)=0.01 & m_{2}(C)=0.99
\end{array}
$$

Through the calculation using D-S theory, the conflict coefficient $k$ is 0.9999 , and the fusion result is:

$\mathrm{m}(A)=0 \quad \mathrm{~m}(B)=1 \quad \mathrm{~m}(C)=0$

It can be seen that the BPAs of proposition $B$ assigned by two pieces of evidence are very small, but the fusion result fully supports proposition $B$, which is the counterintuitive result in practice.

\section{(2) Complete Conflict}

In a multisensor system, it is assumed that the frame is $\Theta=\{A, B\}$ and that there are three bodies of evidence.

$$
\begin{array}{rlr}
E_{1}: m_{1}(A)=0.90 & m_{1}(B)=0.10 \\
E_{2}: m_{2}(A)=0.00 & m_{2}(B)=1.00 \\
E_{3}: m_{3}(A)=1.00 & m_{3}(B)=0.00
\end{array}
$$

It is clear that evidence $E_{2}$ and $E_{3}$ completely conflict. The conflict coefficient $k$ is 1 . In this case, Dempster's rule of combination cannot be applied because the normalized coefficient $1 / 1-k$ is 0 .

\section{(3) "One Ballot Veto" Conflict}

In a multisensor system, assume that the frame is $\Theta=\{A$, $B$ \} and proposition $A$ is true. There are three bodies of evidence.

$$
\begin{array}{ll}
E_{1}: m_{1}(A)=0.90 & m_{1}(B)=0.10 \\
E_{2}: m_{2}(A)=0.80 & m_{2}(B)=0.20 \\
E_{3}: m_{3}(A)=0.00 & m_{2}(B)=1.00
\end{array}
$$

Evidence $E_{1}, E_{2}$ all conformably allocate the largest BPA to proposition $A$. However, evidence $E_{3}$ completely denies proposition $A$, which highly conflicts with evidence $E_{1}, E_{2}$. Applying Dempster's rule of combination, the conflict coefficient and the fusion result are obtained as follows.

$$
k=0.98 \quad m(A)=0 \quad m(B)=1
$$

It is clear that the support of proposition $A$ in the fusion result is zero, which is contrary to the true result. As long as one piece of evidence contradicts a certain proposition, no matter how much the other pieces of evidence support it, the fusion result of the proposition is 0 . The situation is named the "one ballot veto" conflict.

\section{(4) Pseudo Complete Conflict}

Pseudocomplete conflict is very similar to complete conflict. There are two main differences between them. One is that many pieces of evidence are consistent, and only a few abnormal pieces of evidence exist in the case of pseudocomplete conflict. The other is that D-S theory cannot be applied to complete conflict. Although D-S theory can fuse the bodies of evidence in pseudocomplete conflict situations, it often fails to obtain the correct results, such as in the following example.

In a multisensor system, assume that the frame is $\Theta=\{A, B, C\}$ and proposition $A$ is true. There are three bodies of evidence.

$$
\begin{array}{lll}
E_{1}: m_{1}(A)=0.55 & m_{1}(B)=0.25 & m_{1}(C)=0.20 \\
E_{2}: m_{2}(A)=0.10 & m_{2}(B)=0.89 & m_{2}(C)=0.01 \\
E_{3}: m_{3}(A)=0.60 & m_{3}(B)=0.20 & m_{3}(C)=0.20
\end{array}
$$

Evidence $E_{1}$ and $E_{3}$ are similar, while evidence $E_{2}$ conflicts with them. Applying Dempster's rule of combination, the fusion result is shown below.

$\mathrm{m}(A)=0.4223, \quad m(B)=0.5696 \quad m(C)=0.0051$

It is clear that the support of proposition $B(0.5696)$ is greater than that of proposition $A(0.4223)$. It seems that proposition $B$ is true, but proposition $A$ is actually the true proposition. Therefore, the correct result cannot be produced by the application of D-S theory in the situation.

\section{Evaluation indicators for the improvement methods}

To better improve the performance of Dempster's rule of combination, many researchers have proposed various improvement methods [42]. Whether these methods can be widely used needs to be tested. The commonly used test is based on only whether the method can correctly identify the real target, while it lacks specific quantitative indicators. Based on the research of typical improved methods, four indicators are proposed in the paper to evaluate the improvement methods.

\section{(1) Identifying the real target}

A good improvement method should first be able to fuse the bodies of evidence in various situations as much as possible to identify the real target. If a method cannot 
obtain the correct result when fusing the bodies of evidence in some cases, the scope of its application will be limited, and the performance of the method will be questioned. Therefore, correctly identifying the target is the basic condition for evaluating the improvement methods.

\section{(2) Uncertain interval value}

The uncertain interval value indicates the uncertainty of the support degree of the recognized target. The greater the value is, the greater the uncertainty of the recognized target, which will increase the risk of incorrectly identifying the target. The uncertain interval value is defined as follows.

$L(A)=P l(A)-\operatorname{Bel}(A)$ where $L(A)$ is the uncertainty interval value for identifying target $A ; \operatorname{Bel}(A)$ is the belief function for identifying target $A ; \operatorname{Pl}(A)$ is the plausibility function for identifying target $A$. The smaller the value of the uncertainty interval is, the better the performance of the method.

\section{(3) Differentiation value}

The differentiation value is the degree of differentiation in the support degree between the real target and the interfering targets. The smaller the value is, the less obvious the difference in the support degree for different recognized targets, which is not conducive to decision making because the real target is easily disturbed by the targets whose support degree are close to that of the real target. The differentiation value is obtained according to Eq. (8).

$\mathrm{D}=\operatorname{Bel}\left(A^{\prime}\right)-\max _{A^{\prime} \neq A_{j}} \operatorname{Bel}\left(A_{j}\right)$

Table 1 The relevant information of various examples

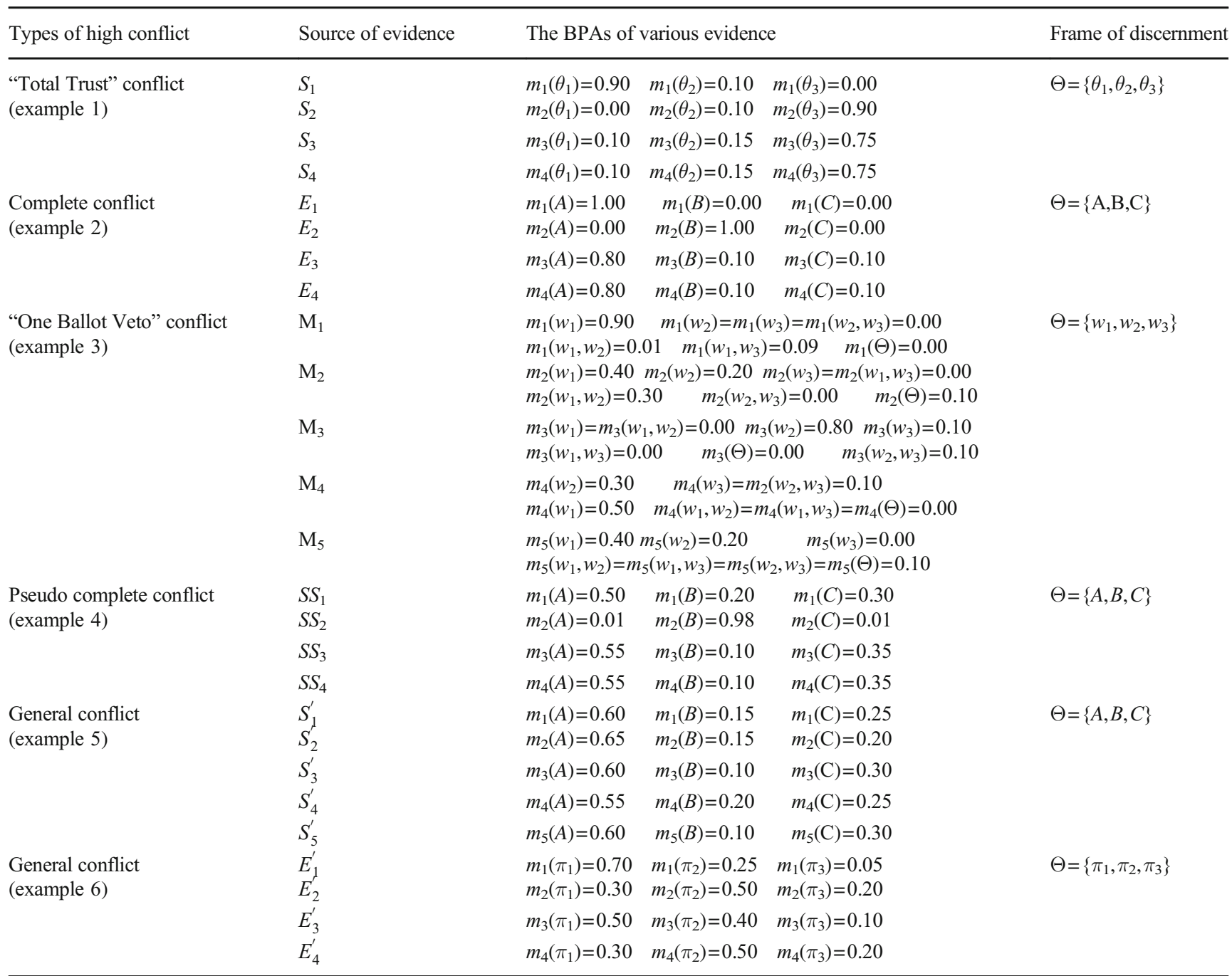


Table 2 Fusion results of various methods for different examples under two pieces of evidence

Types of high Evidence Methods Belief function of the target to be identified conflict
Identified target/real target
Uncertainty interval $\mathrm{D}$ value The value

unknown degree

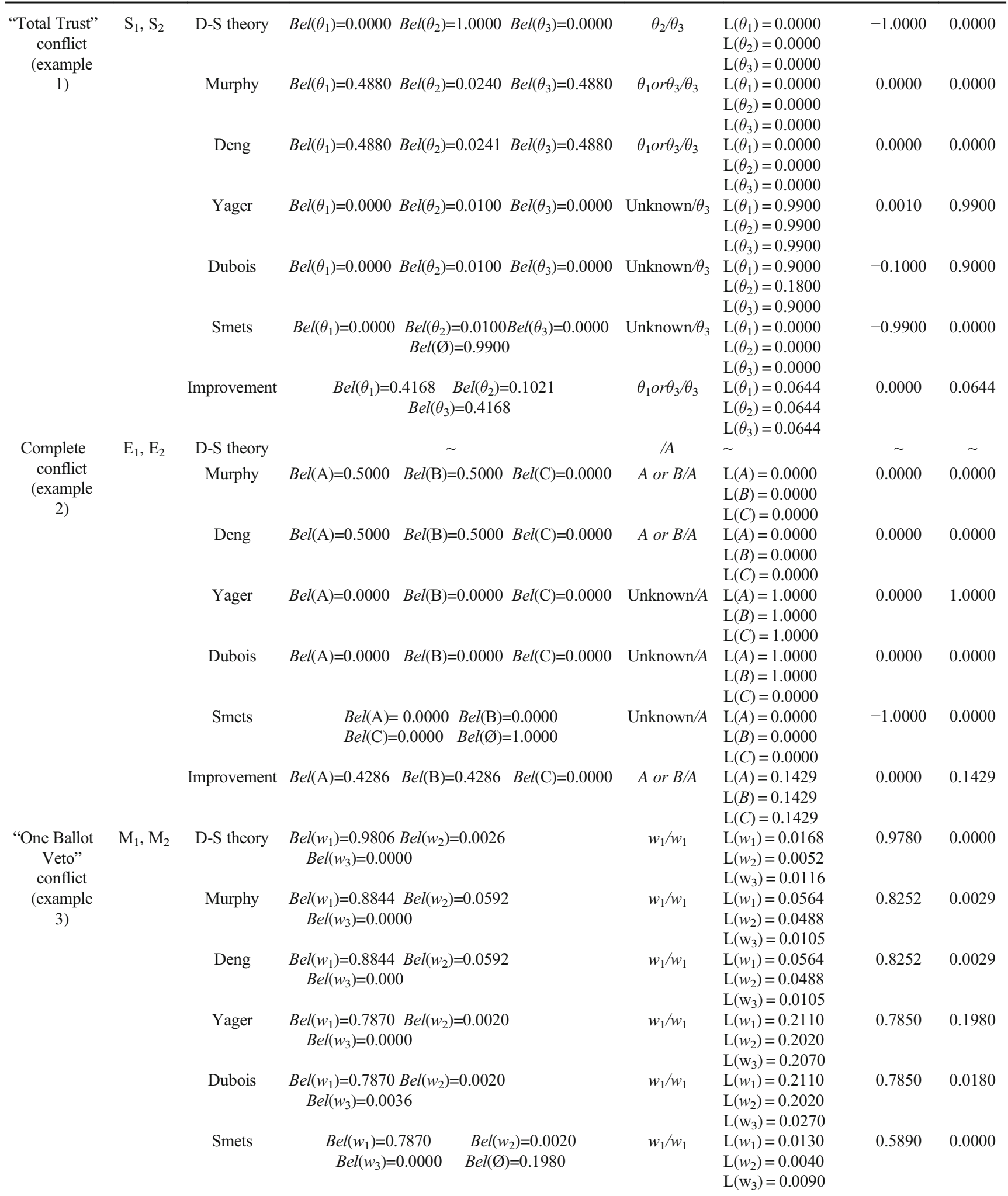


Table 2 (continued)

Types of high Evidence Methods Belief function of the target to be identified conflict
Identified target/real target

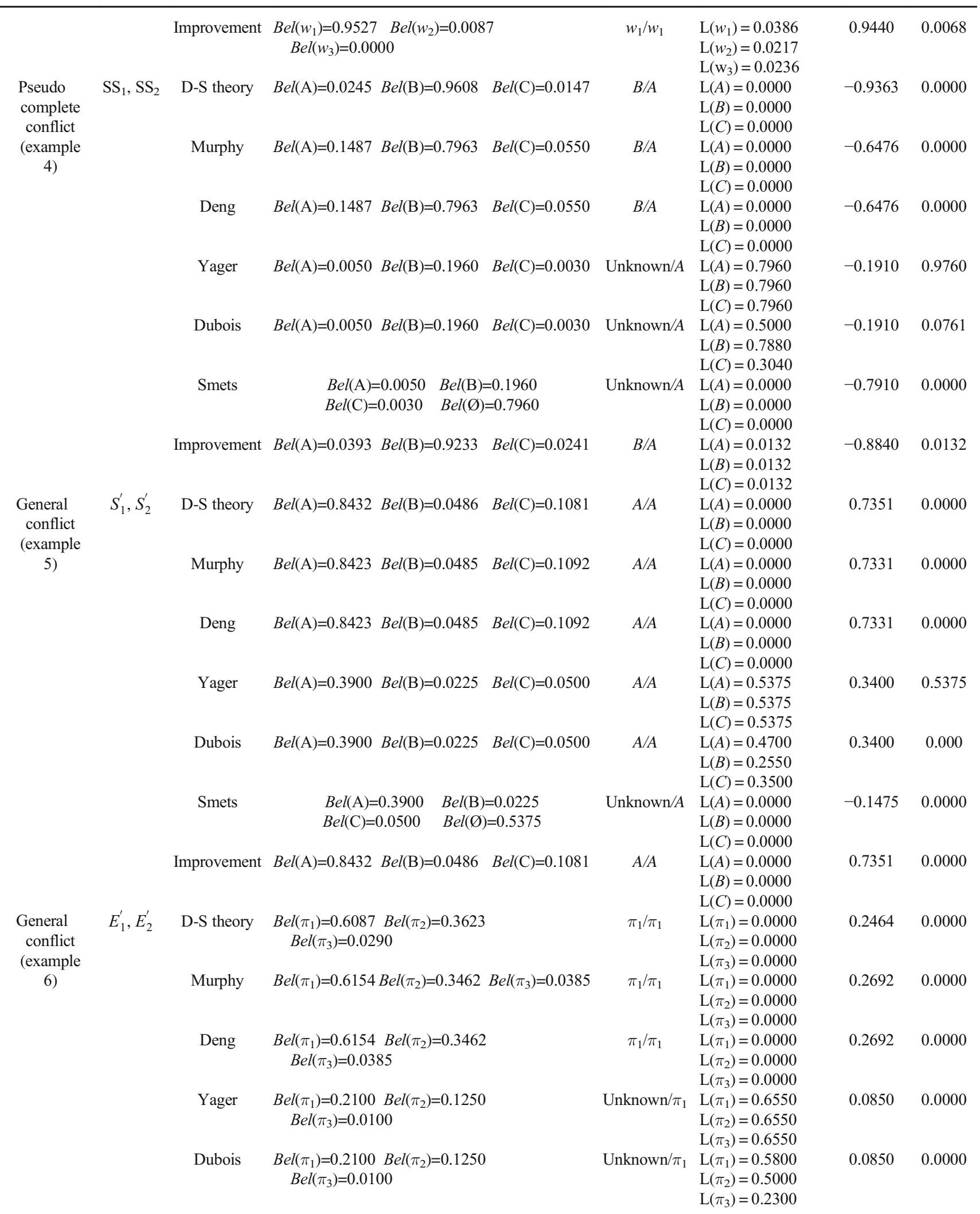


Table 2 (continued)

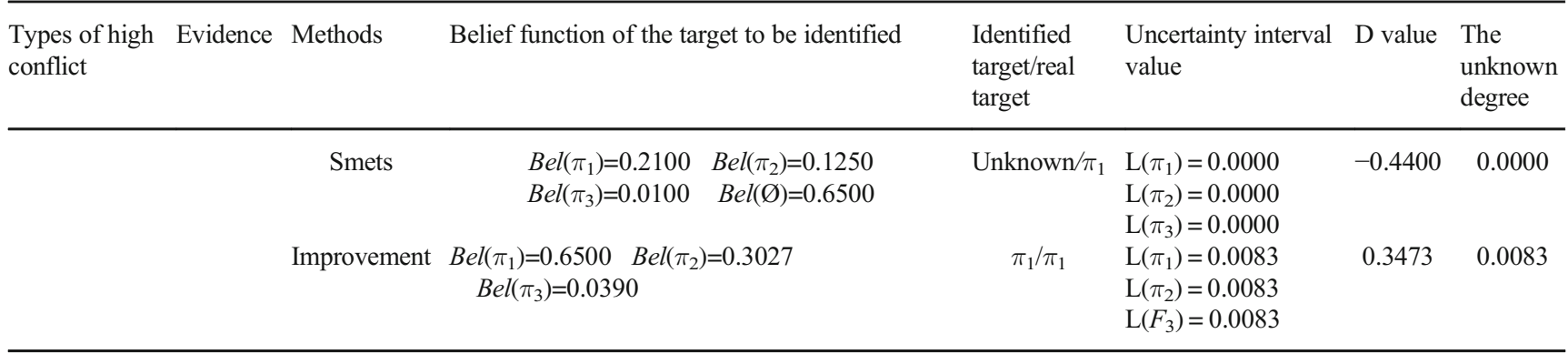

where $\mathrm{D}$ is the differentiation value; $\operatorname{Bel}\left(A^{\prime}\right)$ is the belief function of the real target. The greater the differentiation value is, the better the performance of the method.

\section{(4) The unknown degree}

The unknown degree relates to a frame of discernment and can be measured by $m(\Theta)$ which is the BPA of the focal element $\Theta$. The smaller the value of $m(\Theta)$ is, the smaller the unknown degree of the fusion result, which makes it easier to make right decisions in the actual decision-making process, and vice versa. One of the advantages of multisource information fusion is that it can significantly decrease the unknown degree of fusion results. If a fusion method fails to achieve this effect, it will lose its value in practical applications.

\section{The proposed method}

The proposed method is as follows. First, the consistency degree and conflict intensity between the bodies of evidence are measured. Second, the unreliability of the evidence is calculated. Third, the redistribution equation of the BPA is constructed. Then, to avoid excessive redistribution of the BPA, the precision degree obtained by information entropy is used as the correction factor to modify the BPA for the second time. Finally, Dempster's rule of combination is used to fuse the modified BPA, and the recognition target is determined based on the fusion results.

\subsection{Consistency and conflict of evidence}

Definition 3.1 (Consistency degree and Conflict degree [46]). Let $m_{1}$ and $m_{2}$, based on the same frame of discernment $\Theta$, be two BPAs provided by two pieces of evidence $E_{1}$ and $E_{2}, A_{i}$ and $A_{j}$ belong to $2^{\Theta}$, which is the power set of $\Theta$.

$$
\begin{aligned}
& H\left(m_{1}, m_{2}\right)=\sum_{A_{i} \cap A_{j} \neq \varnothing} m_{1}\left(A_{i}\right) m_{2}\left(A_{j}\right) \frac{\left|A_{i} \cap A_{j}\right|}{\left|A_{i} \cup A_{j}\right|} \\
& C\left(m_{1}, m_{2}\right)=\sum_{A_{i} \cap A_{j=\varnothing}} m_{1}\left(A_{i}\right) m_{2}\left(A_{j}\right)
\end{aligned}
$$

where $H\left(m_{1}, m_{2}\right)$ is the consistency degree between $E_{1}$ and $E_{2}$, which describes the consistency degree of corresponding focal elements between two bodies of evidence; $C\left(m_{1}, m_{2}\right)$ measures the conflict degree between two bodies of evidence, which indicates the degree of conflict in the distribution of the support degree among the focus elements.

If there are more than two pieces of evidence, the consistency degree of the $i$ th piece of evidence can be obtained based on Eq. (11), where $q$ is the number of pieces of evidence.

$$
R_{i}=\sum_{\substack{j=1 \\ j \neq i}}^{q \neq i}\left(m_{i}, m_{j}\right)
$$

Similarly, the conflict degree of the ith piece of evidence can be obtained, as shown in the equation below.

$$
K_{i}=\sum_{\substack{j=1 \\ j \neq i}}^{q} C\left(m_{1}, m_{2}\right)
$$

Based on Eqs. (11) and (12), the conflict intensity of the ith piece of evidence can be obtained.

$C I_{i}=\frac{K_{i}}{K_{i}+R_{i}}$

The conflict intensity $\mathrm{CI}_{i}$ is the degree of divergence between the $i$ th piece of evidence and other pieces of evidence. The greater the divergence, the more likely the evidence is to be inconsistent with other bodies of evidence. If there is no prior knowledge to determine the reliability and importance of the evidence, it is unreasonable to arbitrarily discard the evidence. One of the ways to effectively utilize the evidence of divergence is to assign a partial BPA to the focal element $\Theta$. Moreover, the more divergent the evidence is, the greater the likelihood of assigning a value to the focal element $\Theta$, and the greater the value assigned to it. 
Fig. 1 Belief value of the real target fused by different methods for different examples under two pieces of evidence

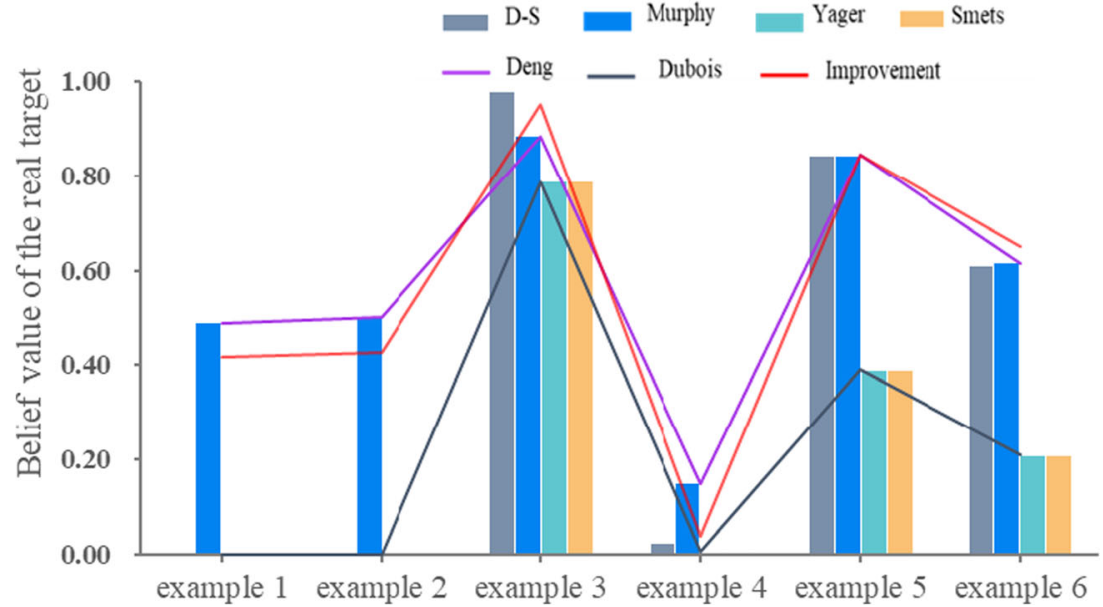

\subsection{The unreliability of evidence}

Because of the interference of many factors, each piece of evidence may be unreliable. Without prior knowledge related to the evidence, the unreliability of the evidence is mainly estimated based on the "majority of principle" [43]. Generally, the higher the consistency degree between the BPAs of a piece of evidence and the BPAs of other bodies of evidence, the more reliable the evidence is, and the lower the consistency degree, the less reliable the evidence is. The unreliability of evidence is obtained by the following formulas $[43,47]$.

$$
\begin{gathered}
r_{B P A}\left(m_{i}, m_{j}\right)=\frac{H\left(m_{i}, m_{j}\right)}{\sqrt{H\left(m_{i}, m_{i}\right) \cdot H\left(m_{j}, m_{j}\right)}} \\
U\left(m_{i}\right)=\frac{\sum_{\substack{j=1 \\
j \neq i}}^{q}\left(1-r_{B P A}\left(m_{i}, m_{j}\right)\right)}{\sum_{\substack{i=1 \\
\sum_{j=1}^{q} \\
j \neq i}}^{q}\left(1-r_{B P A}\left(m_{i}, m_{j}\right)\right)}
\end{gathered}
$$

where $r_{B P A}$ is the correlation coefficient between $E_{\mathrm{i}}$ and $E_{\mathrm{j}}$; $U\left(m_{i}\right)$ is the unreliability of the $i t h$ piece of evidence.

\subsection{Redistribution of the basic probability assignment}

Based on the conflict intensity and the unreliability of the evidence, the redistribution equation of BPAs is constructed to modify the original BPAs.

$m_{i}(\Delta)=\alpha \cdot C I_{i} \cdot U\left(m_{i}\right), \quad 0 \leq m_{i}(\Delta) \leq 1$

$\left\{\begin{array}{cc}m_{i}^{\prime}\left(A_{s}\right)=\left(1-m_{i}(\Delta)\right) \cdot m_{i}\left(A_{s}\right) & A_{s} \neq \Theta \\ m_{i}^{\prime}\left(A_{s}\right)=m_{i}\left(A_{s}\right)+m_{i}(\Delta) & A_{s}=\Theta\end{array}\right.$

where $m_{i}^{\prime}$ is the BPA after redistribution of the $i t h$ piece of evidence; $m_{i}(\Delta)$ is the BPA transferred from other propositions to $\Theta$ for the ith piece of evidence; and $\alpha$ is the adjusted coefficient. The paper suggests that the value of $\alpha$ is divided into three cases: (i) when it can be determined that the original BPAs of the $i t h$ piece of evidence is correct, the value of $\alpha$ is zero; (ii) when the proposition corresponding to the maximum basic probability given by the evidence is not the same as the proposition corresponding to the maximum basic probability given by any other evidence, and the BPA of the proposition given by the evidence is close to 1 , the value of $\alpha$ is one; and (iii) in other cases, the value of $\alpha$ is 0.5 . Note that when the value of $\alpha$ is zero, the original BPAs remain unchanged, and the proposed
Fig. 2 Belief value of the real target fused by different methods for different examples under three pieces of evidence

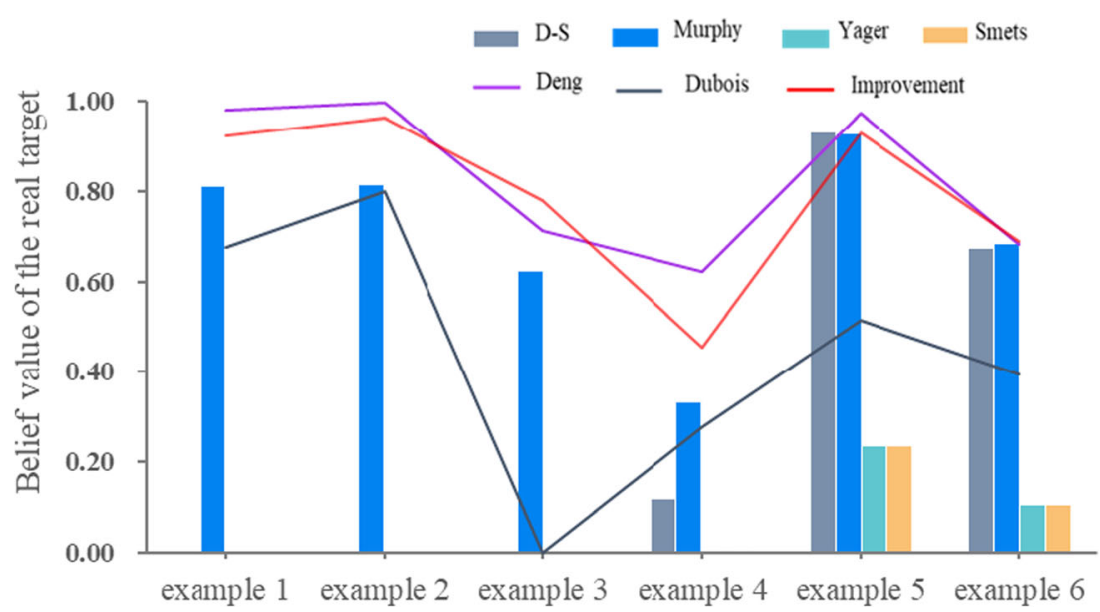


Fig. 3 Belief value of the real target fused by different methods for different examples under four pieces of evidence

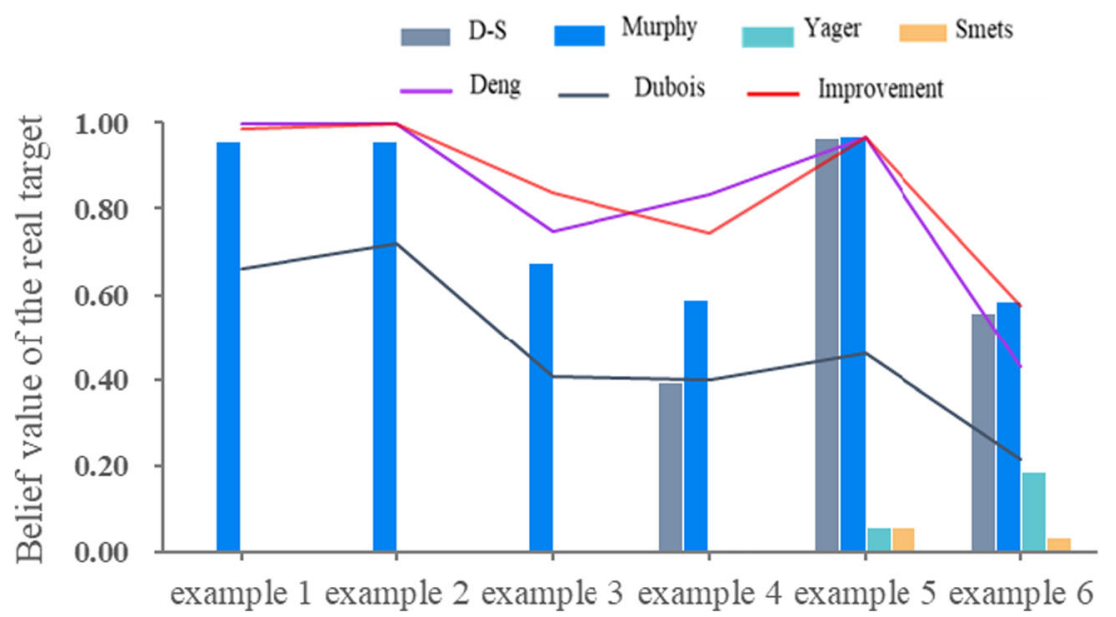

method becomes the D-S evidence method, i.e., D-S evidence method can be seen as a special case of the proposed method.

\subsection{Modification of BPAs after redistribution based on the degree of precision}

Although the initial BPAs are modified by the above equations, the BPAs of some propositions may be overcorrected, which can distort the original evidence information. Moreover, if the BPA transferred to the focal element $\Theta$ is excessive, the ambiguity of the evidence will be increased. To reduce this adverse effect, the BPAs of the propositions need to be modified for a second time.

The primary focal element, which is the proposition with the maximum BPA, covers the maximum information volume of the evidence. If the primary focal element does not change after redistribution and there is no significant change in the BPA of the primary focal element and the BPA of the focal element $\Theta$, then the original information does not change substantially. To avoid excessive redistribution of the BPAs, the redistributive BPAs are revised for a second time while ensuring that the primary focal element corresponding to the evidence remains unchanged.

The greater the difference between the BPA of the primary focal element corresponding to a piece of evidence and the
BPAs of other propositions corresponding to the evidence is, the more precision the information contained in this evidence. However, the more precise the evidence, the more likely the BPAs will overcorrect. Therefore, the issue can be solved from the perspective of the precision of the evidence. Information entropy is an effective way to calculate the precision of evidence. In this paper, information entropy theory is used to calculate the precision degree of each piece of evidence. Then, the precision degree is used as the transfer factor to transfer a part of the BPA of focal element $\Theta$ to the primary focal element, which avoids the problem caused by the redistribution of the BPAs. The relevant formulas are as follows.

$$
\begin{aligned}
F_{i} & =-\frac{1}{\log _{2} n} \sum_{s}^{n} m_{i}\left(A_{s}\right) \log _{2} m_{i}\left(A_{s}\right) \\
F_{i}^{\prime} & =\frac{1-F_{i}}{\sum_{k=1}^{q}\left(1-F_{k}\right)}
\end{aligned}
$$

$$
\left\{\begin{array}{lrr}
m_{i}^{\prime \prime}\left(A_{s}\right)=m_{i}^{\prime}\left(A_{s}\right)+F_{i}^{\prime} \cdot m_{i}(\Delta) & m_{i}^{\prime}\left(A_{s}\right)=\max _{t=1,2, \cdots n} & m_{i}^{\prime}\left(A_{t}\right), A_{s} \neq \Theta \\
m_{i}^{\prime \prime}\left(A_{s}\right)=m_{i}^{\prime}\left(A_{s}\right) & m_{i}^{\prime}\left(A_{s}\right) \neq \max _{t=1,2, \cdots n} & m_{i}^{\prime}\left(A_{t}\right), A_{s} \neq \Theta \\
m_{i}^{\prime \prime}\left(A_{s}\right)=m_{i}^{\prime}\left(A_{s}\right)-F_{i}^{\prime} \cdot m_{i}(\Delta) & A_{s}=\Theta
\end{array}\right.
$$

Fig. 4 Uncertainty interval value of various methods for different examples under two pieces of evidence

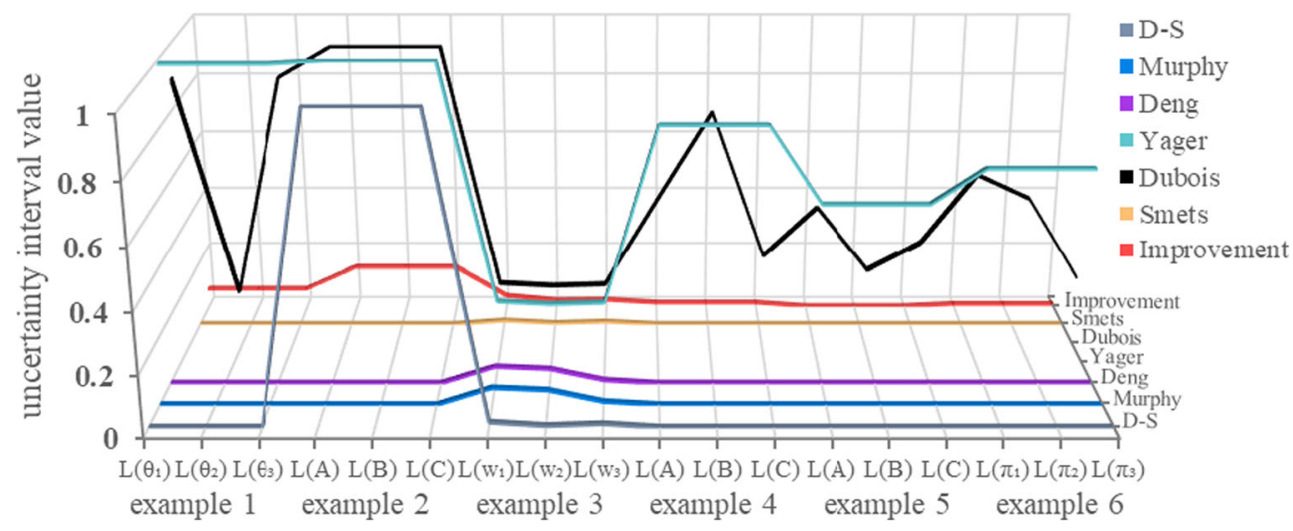


Fig. 5 Uncertainty interval value of various methods for different examples under three pieces of evidence
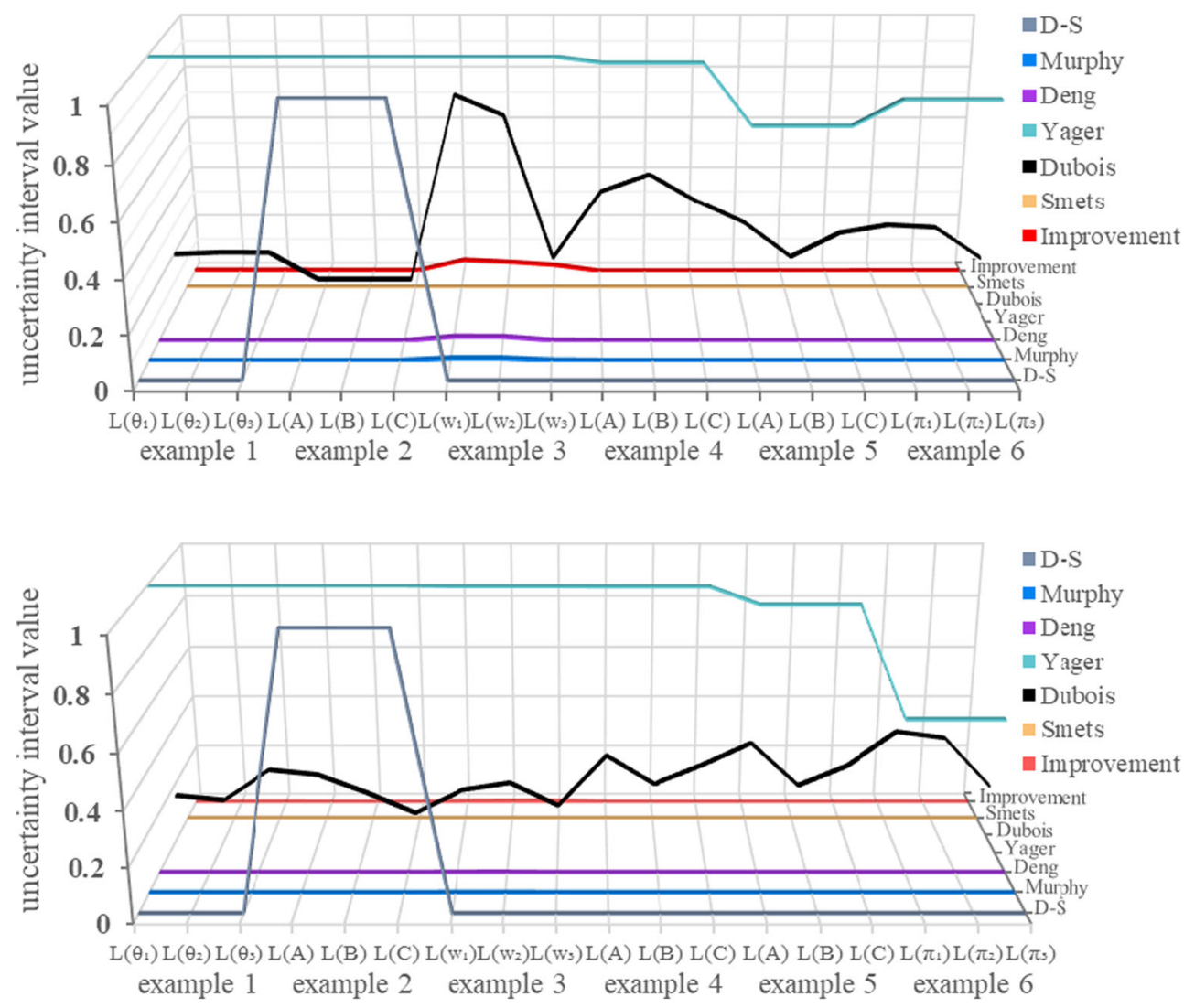

Fig. 6 Uncertainty interval value of various methods for different examples under four pieces of evidence where $F_{i}$ and $\mathrm{F}_{i}^{\prime}$ are the entropy value and the precision degree of the $i$ th piece of evidence, respectively; $m_{i}^{\prime \prime}$ is the final modified BPA of all the propositions corresponding to the $i t h$ piece of evidence.

Based on the final modified BPAs, Dempster's rule of combination is used to combine multisource evidence. Then, Eq. (3) is used to calculate the belief function of each proposition. The identification result is determined based on the principle of maximum membership.

$F(A)=\max _{A_{i} \in \Theta} \operatorname{Bel}\left(A_{i}\right)$

Fig. $7 \mathrm{D}$ values of various methods for different examples under two pieces of evidence where $F(A)$ is the final identification result. An algorithm flowchart of the proposed method is shown below.

\section{Example and analysis}

\subsection{Conflict evidence fusion}

The paper holds that a good improvement method can deal with not only highly conflicting evidence but also general conflicting evidence. To demonstrate the feasibility and

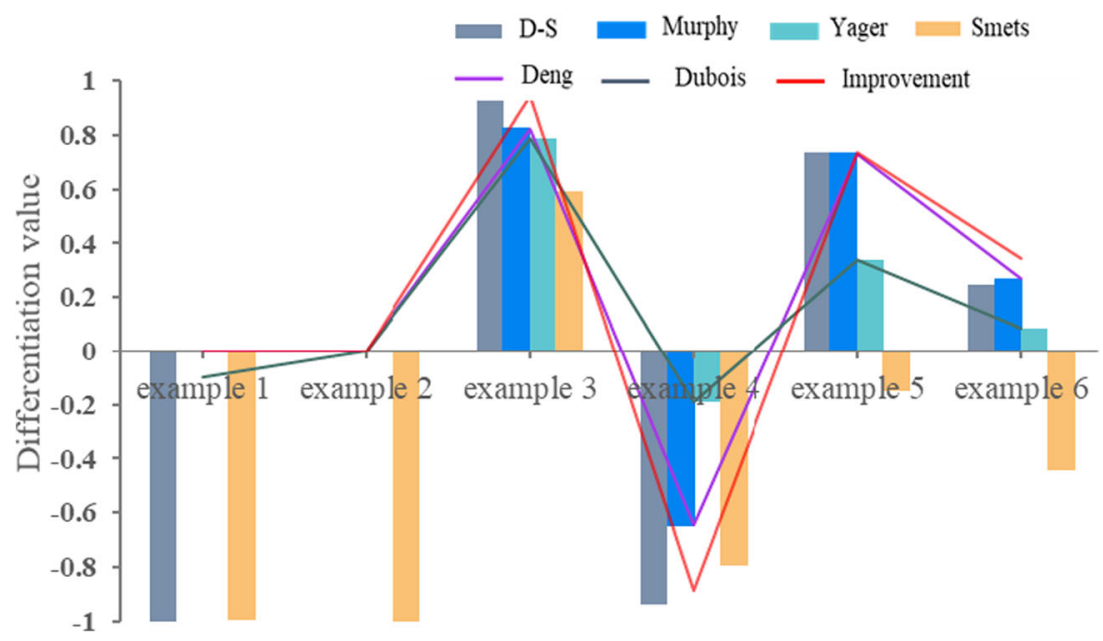


Fig. 8 D values of various methods for different examples under three pieces of evidence

Fig. $9 \mathrm{D}$ values of various methods for different examples under four pieces of evidence

Fig. 10 The unknown degree of various methods for different examples under two pieces of evidence
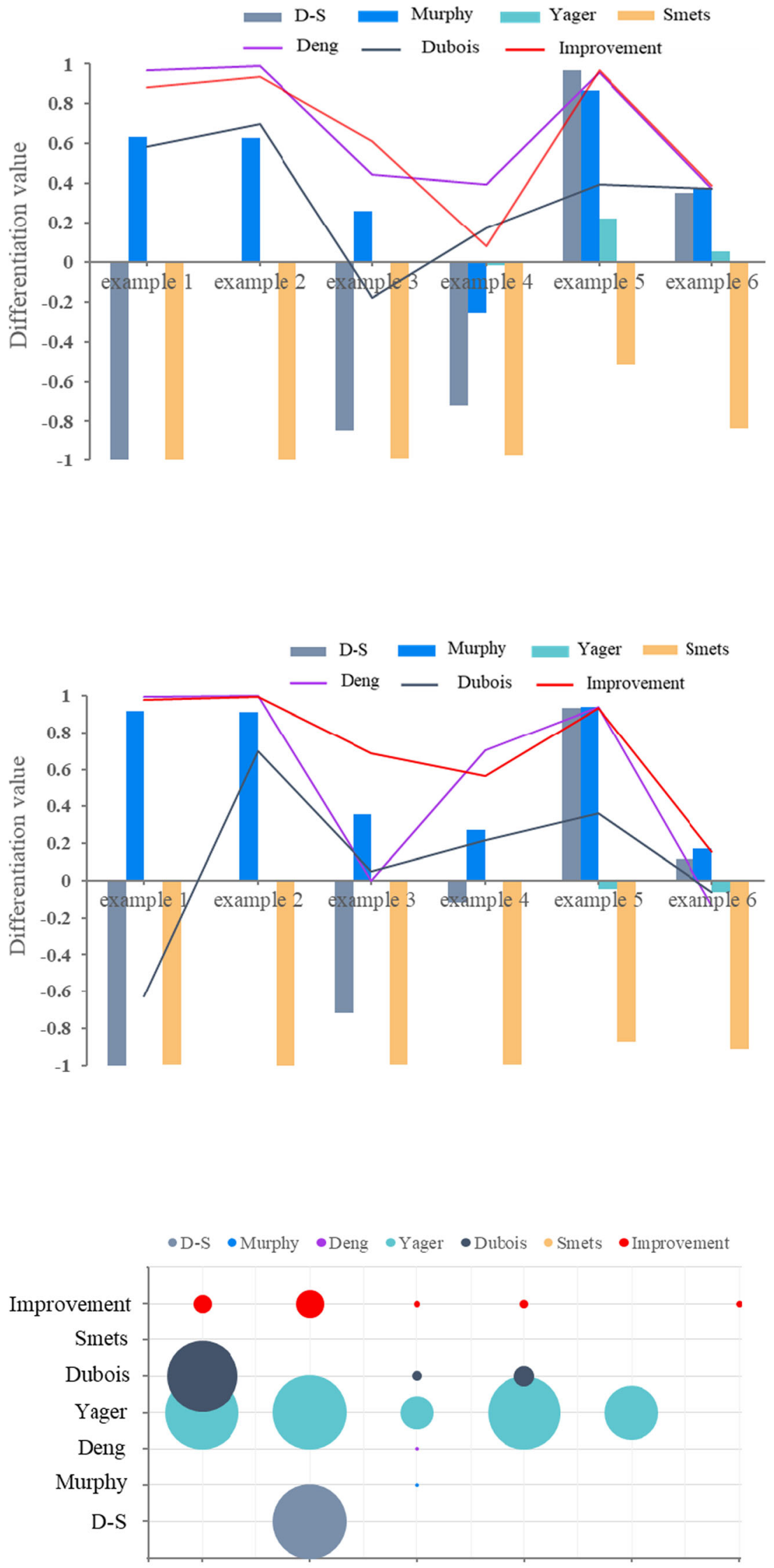

example 1 example 2 example 3 example 4 exampı 5 example 6 
Fig. 11 The unknown degree of various methods for different examples under three pieces of evidence

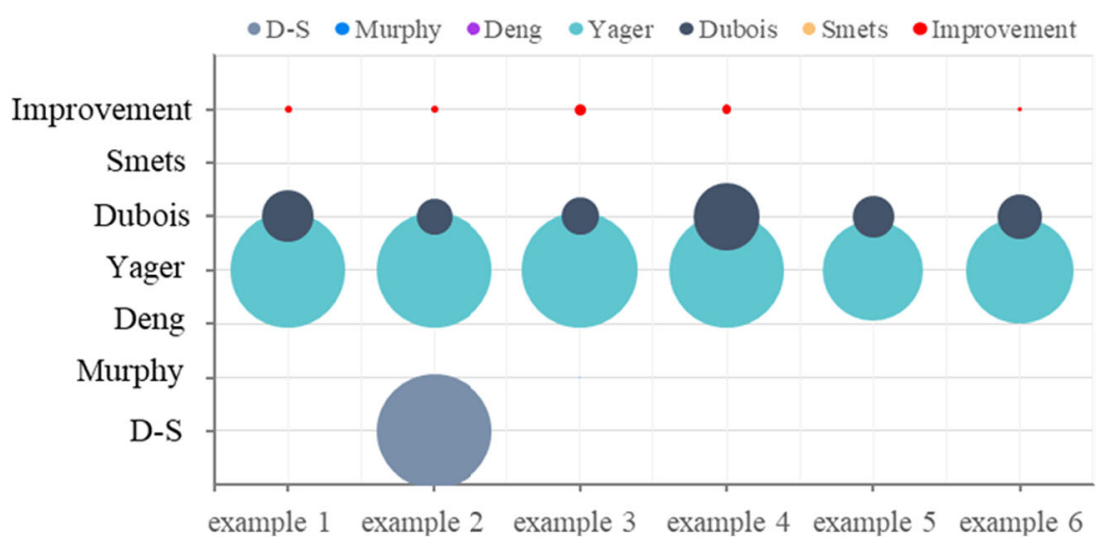

effectiveness of the proposed method, various examples are selected. These examples include four types of highly conflicting evidence (introduced in section 2.2) and general conflicting evidence. The fusion results of each example are compared with those of typical methods, which include D-S theory, Murphy's method [29], Deng's method [30], Yager's method [24], Dubois' method [25], and Smets' method [38]. The example data are from [30, 48-50], and these data from various sources are turned into BPAs, which are shown in Table 1. There are multiple pieces of evidence in each example. To compare the performance of various methods in detail, the different amounts of evidence in each example are fused separately. The detailed fusion results are shown in Tables 2, 3, 4, 5. Figures 1, 2, 3, 4, 5, 6, 7, 8, 9, 10, 11 and 12 show the indicators based on the fusion results of the various methods under different amounts of evidence.

According to Eq. (21), the belief function is the basis for identifying the target. The larger the belief value of the target to be identified is, the greater the degree of support for the target. The following conclusions can be drawn from Fig. 1 when fusing two pieces of evidence: (1) the belief values of the real targets obtained by Yager's method, Smets' method and Dubois' method are significantly lower than those obtained by Murphy's method, the proposed method and Deng's method; (2) the belief values of the real targets obtained by D-S theory, Yager's method, Smets' method and Dubois' method are 0 in examples 1 and 2; and (3) the belief values of the real target obtained by all methods are very small in example 4 . According to Table 2 in the appendix, all these methods fail to identify the real targets in example 1, example 2 and example 4, and Yager's method, Smets' method and Dubois' method cannot also identify the real target in example 6. Murphy's method, the proposed method and Deng's method are able to obtain the real targets in examples 3,5 and 6, moreover, the belief values of the real targets obtained by the proposed are higher than the two method in the three examples

The following conclusions can be drawn from Fig. 2 when fusing three pieces of evidence: (1) the belief values of the real targets obtained by the proposed method and Deng's method are obviously higher than those obtained by other methods; and (2) the difference between the belief values obtained by the proposed method and Deng's method various across examples. Based on Table 3 in the appendix, only the proposed method and Deng's method can obtain the real targets in all examples, while the other methods cannot identify the real targets in all the examples above, for example, Murphy's method fails to identify the real target in example 4.

The following conclusions can be drawn from Fig. 3 when fusing four pieces of evidence: (1) The belief values of the real targets obtained by the proposed method, Deng's method and Murphy's method are obviously higher than those obtained by other methods; and (2) the belief values of the real targets
Fig. 12 The unknown degree of various methods for different examples under four pieces of evidence

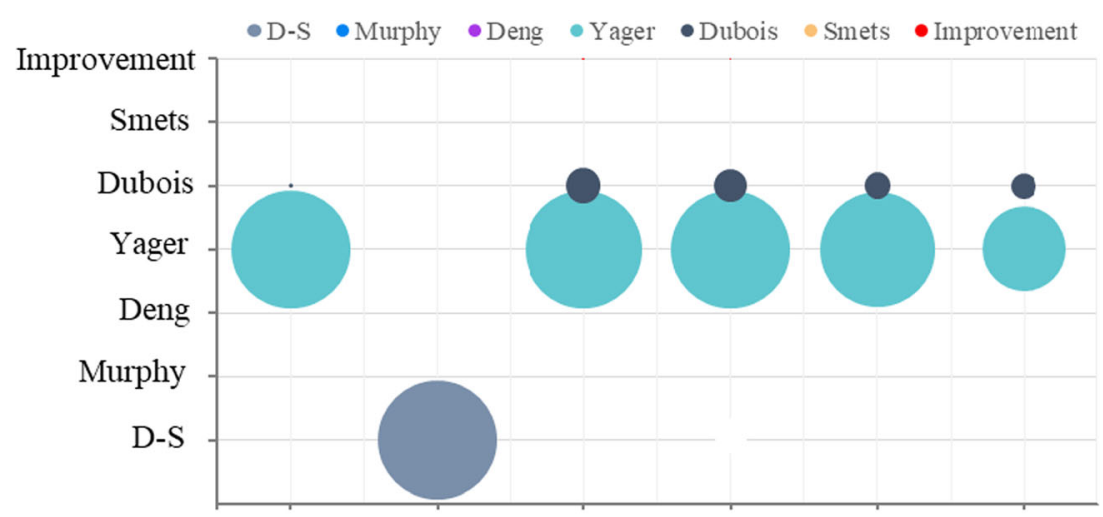

example 1 example 2 example 3 example 4 example 5 example 6 
Table 3 Fusion results of various methods for different examples under three pieces of evidence

\begin{tabular}{|c|c|c|c|c|c|c|c|}
\hline $\begin{array}{l}\text { Types of high } \\
\text { conflict }\end{array}$ & Evidence & Methods & Belief function of the target to be identified & $\begin{array}{l}\text { Identified } \\
\text { target/real } \\
\text { target }\end{array}$ & $\begin{array}{l}\text { Uncertainty interval } \\
\text { value }\end{array}$ & $\mathrm{D}$ value & $\begin{array}{l}\text { The } \\
\text { unknown } \\
\text { degree }\end{array}$ \\
\hline \multirow{7}{*}{$\begin{array}{c}\text { "Total Trust" } \\
\text { conflict } \\
\text { (example } \\
1)\end{array}$} & \multirow[t]{7}{*}{$\mathrm{S}_{1}, \mathrm{~S}_{2}, \mathrm{~S}_{3}$} & D-S theory & $\begin{array}{l}\operatorname{Bel}\left(\theta_{1}\right)=0.0000 \quad \operatorname{Bel}\left(\theta_{2}\right)=1.0000 \\
\operatorname{Bel}\left(\theta_{3}\right)=0.0000\end{array}$ & $\theta_{2} / \theta_{3}$ & $\begin{array}{l}\mathrm{L}\left(\theta_{1}\right)=0.0000 \\
\mathrm{~L}\left(\theta_{2}\right)=0.0000 \\
\mathrm{~L}\left(\theta_{3}\right)=0.0000\end{array}$ & -1.0000 & 0.0000 \\
\hline & & Murphy & $\begin{array}{l}\operatorname{Bel}\left(\theta_{1}\right)=0.1807 \quad \operatorname{Bel}\left(\theta_{2}\right)=0.0077 \\
\quad \operatorname{Bel}\left(\theta_{3}\right)=0.8116\end{array}$ & $\theta_{3} / \theta_{3}$ & $\begin{array}{l}\mathrm{L}\left(\theta_{1}\right)=0.0000 \\
\mathrm{~L}\left(\theta_{2}\right)=0.0000 \\
\mathrm{~L}\left(\theta_{3}\right)=0.0000\end{array}$ & 0.6309 & 0.0000 \\
\hline & & Deng & $\begin{array}{l}\operatorname{Bel}\left(\theta_{1}\right)=0.0131 \quad \operatorname{Bel}\left(\theta_{2}\right)=0.0051 \\
\quad \operatorname{Bel}\left(\theta_{3}\right)=0.9818\end{array}$ & $\theta_{3} / \theta_{3}$ & $\begin{array}{l}\mathrm{L}\left(\theta_{1}\right)=0.0000 \\
\mathrm{~L}\left(\theta_{2}\right)=0.0000 \\
\mathrm{~L}\left(\theta_{3}\right)=0.0000\end{array}$ & 0.9687 & 0.0000 \\
\hline & & Yager & $\begin{array}{l}\operatorname{Bel}\left(\theta_{1}\right)=0.0000 \quad \operatorname{Bel}\left(\theta_{2}\right)=0.0015 \\
\operatorname{Bel}\left(\theta_{3}\right)=0.0000\end{array}$ & Unknown $/ \theta_{3}$ & $\begin{array}{l}\mathrm{L}\left(\theta_{1}\right)=0.9985 \\
\mathrm{~L}\left(\theta_{2}\right)=0.9985 \\
\mathrm{~L}\left(\theta_{3}\right)=0.9985\end{array}$ & 0.0015 & 0.9985 \\
\hline & & Dubois & $\begin{array}{l}\operatorname{Bel}\left(\theta_{1}\right)=0.0900 \operatorname{Bel}\left(\theta_{2}\right)=0.0285 \\
\operatorname{Bel}\left(\theta_{3}\right)=0.6750\end{array}$ & $\theta_{3} / \theta_{3}$ & $\begin{array}{l}\mathrm{L}\left(\theta_{1}\right)=0.1990 \\
\mathrm{~L}\left(\theta_{2}\right)=0.2065 \\
\mathrm{~L}\left(\theta_{3}\right)=0.2055\end{array}$ & 0.5850 & 0.1980 \\
\hline & & Smets & $\begin{array}{l}\operatorname{Bel}\left(\theta_{1}\right)=0.0000 \operatorname{Bel}\left(\theta_{2}\right)=0.0015 \\
\operatorname{Bel}\left(\theta_{3}\right)=0.0000 \operatorname{Bel}(\varnothing)=0.9985\end{array}$ & Unknown $/ \theta_{3}$ & $\begin{array}{l}\mathrm{L}\left(\theta_{1}\right)=0.0000 \\
\mathrm{~L}\left(\theta_{2}\right)=0.0000 \\
\mathrm{~L}\left(\theta_{3}\right)=0.0000\end{array}$ & -0.9985 & 0.0000 \\
\hline & & Improvement & $\begin{array}{l}\operatorname{Bel}\left(\theta_{1}\right)=0.0314 \quad \operatorname{Bel}\left(\theta_{2}\right)=0.0407 \\
\quad \operatorname{Bel}\left(\theta_{3}\right)=0.9240\end{array}$ & $\theta_{3} / \theta_{3}$ & $\begin{array}{l}\mathrm{L}\left(\theta_{1}\right)=0.0039 \\
\mathrm{~L}\left(\theta_{2}\right)=0.0039 \\
\mathrm{~L}\left(\theta_{3}\right)=0.0039\end{array}$ & 0.8833 & 0.0039 \\
\hline \multirow{7}{*}{$\begin{array}{l}\text { Complete } \\
\text { conflict } \\
\text { (example } \\
2 \text { ) }\end{array}$} & \multirow{7}{*}{$\begin{array}{l}\mathrm{E}_{1}, \mathrm{E}_{2} \\
\quad \mathrm{E}_{3}\end{array}$} & D-S theory & $\sim$ & $/ A$ & $\sim$ & $\sim$ & $\sim$ \\
\hline & & Murphy & $\operatorname{Bel}(\mathrm{A})=0.8141 \quad \operatorname{Bel}(\mathrm{B})=0.1858 \operatorname{Bel}(\mathrm{C})=0.0001$ & $A / A$ & $\begin{array}{l}\mathrm{L}(A)=0.0000 \\
\mathrm{~L}(B)=0.0000 \\
\mathrm{~L}(C)=0.0000\end{array}$ & 0.6283 & 0.0000 \\
\hline & & Deng & $\operatorname{Bel}(\mathrm{A})=0.9963 \quad \operatorname{Bel}(\mathrm{B})=0.0035 \operatorname{Bel}(\mathrm{C})=0.0000$ & $A / A$ & $\begin{array}{l}\mathrm{L}(A)=0.0000 \\
\mathrm{~L}(B)=0.0000 \\
\mathrm{~L}(C)=0.0000\end{array}$ & 0.9927 & 1.0000 \\
\hline & & Yager & $\operatorname{Bel}(\mathrm{A})=0.0000 \quad \operatorname{Bel}(\mathrm{B})=0.0000 \operatorname{Bel}(\mathrm{C})=0.0000$ & Unknown/A & $\begin{array}{l}\mathrm{L}(A)=1.0000 \\
\mathrm{~L}(B)=1.0000 \\
\mathrm{~L}(C)=1.0000\end{array}$ & 0.0000 & 1.0000 \\
\hline & & Dubois & $\operatorname{Bel}(\mathrm{A})=0.8000 \quad \operatorname{Bel}(\mathrm{B})=0.1000 \operatorname{Bel}(\mathrm{C})=0.0000$ & $A / A$ & $\begin{array}{l}\mathrm{L}(A)=0.1000 \\
\mathrm{~L}(B)=0.1000 \\
\mathrm{~L}(C)=0.1000\end{array}$ & 0.7000 & 0.1000 \\
\hline & & Smets & $\begin{array}{ll}\operatorname{Bel}(\mathrm{A})=0.0000 & \operatorname{Bel}(\mathrm{B})=0.0000 \\
\operatorname{Bel}(\mathrm{C})=0.0000 & \operatorname{Bel}(\varnothing)=1.0000\end{array}$ & Unknown/A & $\begin{array}{l}\mathrm{L}(A)=0.0000 \\
\mathrm{~L}(B)=0.0000 \\
\mathrm{~L}(C)=0.0000\end{array}$ & -1.0000 & 0.0000 \\
\hline & & Improvement & $\operatorname{Bel}(\mathrm{A})=0.9648 \quad \operatorname{Bel}(\mathrm{B})=0.0269 \operatorname{Bel}(\mathrm{C})=0.0053$ & $A / A$ & $\begin{array}{l}\mathrm{L}(A)=0.0030 \\
\mathrm{~L}(B)=0.0030 \\
\mathrm{~L}(C)=0.0030\end{array}$ & 0.9379 & 0.0030 \\
\hline \multirow{6}{*}{$\begin{array}{c}\text { "One Ballot } \\
\text { Veto" } \\
\text { conflict } \\
\text { (example } \\
3)\end{array}$} & \multirow[t]{6}{*}{$\begin{array}{c}\mathrm{M}_{1}, \mathrm{M}_{2} \\
\mathrm{M}_{3}\end{array}$} & D-S theory & $\begin{array}{l}\operatorname{Bel}\left(w_{1}\right)=0.0000 \operatorname{Bel}\left(w_{2}\right)=0.8475 \\
\quad \operatorname{Bel}\left(w_{3}\right)=0.1525\end{array}$ & $w_{2} / w_{1}$ & $\begin{array}{l}\mathrm{L}\left(w_{1}\right)=0.0000 \\
\mathrm{~L}\left(w_{2}\right)=0.0000 \\
\mathrm{~L}\left(\mathrm{w}_{3}\right)=0.0000\end{array}$ & -0.8475 & 0.0000 \\
\hline & & Murphy & $\begin{array}{l}\operatorname{Bel}\left(w_{1}\right)=0.6223 \operatorname{Bel}\left(w_{2}\right)=0.3639 \\
\quad \operatorname{Bel}\left(w_{3}\right)=0.0049\end{array}$ & $w_{1} / w_{1}$ & $\begin{array}{l}\mathrm{L}\left(w_{1}\right)=0.0081 \\
\mathrm{~L}\left(w_{2}\right)=0.0082 \\
\mathrm{~L}\left(\mathrm{w}_{3}\right)=0.0015\end{array}$ & 0.2584 & 0.0001 \\
\hline & & Deng & $\begin{array}{l}\operatorname{Bel}\left(w_{1}\right)=0.7116 \operatorname{Bel}\left(w_{2}\right)=0.2689 \\
\quad \operatorname{Bel}\left(w_{3}\right)=0.0027\end{array}$ & $w_{1} / w_{1}$ & $\begin{array}{l}\mathrm{L}\left(w_{1}\right)=0.0162 \\
\mathrm{~L}\left(w_{2}\right)=0.0161 \\
\mathrm{~L}\left(\mathrm{w}_{3}\right)=0.0015\end{array}$ & 0.4426 & 0.0002 \\
\hline & & Yager & $\begin{array}{l}\operatorname{Bel}\left(w_{1}\right)=0.0000 \operatorname{Bel}\left(w_{2}\right)=0.0000 \\
\quad \operatorname{Bel}\left(w_{3}\right)=0.0000\end{array}$ & Unknown $/ w_{1}$ & $\begin{array}{l}\mathrm{L}\left(w_{1}\right)=1.0000 \\
\mathrm{~L}\left(w_{2}\right)=1.0000 \\
\mathrm{~L}\left(\mathrm{w}_{3}\right)=1.0000\end{array}$ & 0.0000 & 1.0000 \\
\hline & & Dubois & $\begin{array}{l}\operatorname{Bel}\left(w_{1}\right)=0.0000 \operatorname{Bel}\left(w_{2}\right)=0.1818 \\
\quad \operatorname{Bel}\left(w_{3}\right)=0.0036\end{array}$ & Unknown $/ w_{1}$ & $\begin{array}{l}\mathrm{L}\left(w_{1}\right)=0.8126 \\
\mathrm{~L}\left(w_{2}\right)=0.7359 \\
\mathrm{~L}\left(\mathrm{w}_{3}\right)=0.1850\end{array}$ & -0.1818 & 0.1043 \\
\hline & & Smets & $\begin{array}{cc}\operatorname{Bel}\left(w_{1}\right)=0.0000 & \operatorname{Bel}\left(w_{2}\right)=0.0054 \\
\operatorname{Bel}\left(w_{3}\right)=0.0018 & \operatorname{Bel}(\varnothing)=0.9928\end{array}$ & Unknown $/ w_{1}$ & $\begin{array}{l}\mathrm{L}\left(w_{1}\right)=0.0000 \\
\mathrm{~L}\left(w_{2}\right)=0.0000 \\
\mathrm{~L}\left(\mathrm{w}_{3}\right)=0.0000\end{array}$ & -0.9928 & 0.0000 \\
\hline
\end{tabular}


Table 3 (continued)

Types of high Evidence Methods Belief function of the target to be identified conflict

\begin{tabular}{|c|c|}
\hline $\begin{array}{l}\text { Identified } \\
\text { target/real } \\
\text { target }\end{array}$ & $\begin{array}{l}\text { Uncertainty interval } \mathrm{D} \text { value } \\
\text { value }\end{array}$ \\
\hline
\end{tabular}

\begin{tabular}{|c|c|c|c|c|c|c|c|}
\hline & & Improvement & $\begin{array}{l}\operatorname{Bel}\left(w_{1}\right)=0.7778 \operatorname{Bel}\left(w_{2}\right)=0.1642 \\
\quad \operatorname{Bel}\left(w_{3}\right)=0.0093\end{array}$ & $w_{1} / w_{1}$ & $\begin{array}{l}\mathrm{L}\left(w_{1}\right)=0.0457 \\
\mathrm{~L}\left(w_{2}\right)=0.0371\end{array}$ & 0.6136 & 0.0103 \\
\hline \multirow{7}{*}{$\begin{array}{l}\text { Pseudo } \\
\text { complete } \\
\text { conflict } \\
\text { (example } \\
4)\end{array}$} & \multirow[t]{7}{*}{$\begin{array}{l}\mathrm{SS}_{1}, \mathrm{SS}_{2} \\
\mathrm{SS}_{3}\end{array}$} & D-S theory & $\operatorname{Bel}(\mathrm{A})=0.1175 \quad \operatorname{Bel}(\mathrm{B})=0.8376 \operatorname{Bel}(\mathrm{C})=0.0449$ & $B / A$ & $\begin{array}{l}\mathrm{L}\left(\mathrm{w}_{3}\right)=0.0248 \\
\mathrm{~L}(A)=0.0000 \\
\mathrm{~L}(B)=0.0000 \\
\mathrm{~L}(C)=0.0000\end{array}$ & -0.7201 & 0.0000 \\
\hline & & Murphy & $\operatorname{Bel}(\mathrm{A})=0.3331 \quad \operatorname{Bel}(\mathrm{B})=0.5865 \operatorname{Bel}(\mathrm{C})=0.0804$ & $B / A$ & $\begin{array}{l}\mathrm{L}(A)=0.0000 \\
\mathrm{~L}(B)=0.0000 \\
\mathrm{~L}(C)=0.0000\end{array}$ & -0.2534 & 0.0000 \\
\hline & & Deng & $\operatorname{Bel}(\mathrm{A})=0.6215 \quad \operatorname{Bel}(\mathrm{B})=0.2303 \operatorname{Bel}(\mathrm{C})=0.1482$ & $A / A$ & $\begin{array}{l}\mathrm{L}(A)=0.0000 \\
\mathrm{~L}(B)=0.0000 \\
\mathrm{~L}(C)=0.0000\end{array}$ & 0.3972 & 0.0000 \\
\hline & & Yager & $\operatorname{Bel}(\mathrm{A})=0.0028 \quad \operatorname{Bel}(\mathrm{B})=0.0196 \operatorname{Bel}(\mathrm{C})=0.0011$ & Unknown/A & $\begin{array}{l}\mathrm{L}(A)=0.9766 \\
\mathrm{~L}(B)=0.9766 \\
\mathrm{~L}(C)=0.9766\end{array}$ & -0.0168 & 0.9766 \\
\hline & & Dubois & $\operatorname{Bel}(\mathrm{A})=0.2778 \quad \operatorname{Bel}(\mathrm{B})=0.0984 \operatorname{Bel}(\mathrm{C})=0.1075$ & Unknown/A & $\begin{array}{l}\mathrm{L}(A)=0.4475 \\
\mathrm{~L}(B)=0.5130 \\
\mathrm{~L}(C)=0.4081\end{array}$ & 0.1703 & 0.3358 \\
\hline & & Smets & $\begin{array}{c}\operatorname{Bel}(\mathrm{A})=0.0028 \quad \operatorname{Bel}(\mathrm{B})=0.0196 \operatorname{Bel}(\mathrm{C})=0.0011 \\
\operatorname{Bel}(\varnothing)=0.9766\end{array}$ & Unknown/A & $\begin{array}{l}\mathrm{L}(A)=0.0000 \\
\mathrm{~L}(B)=0.0000 \\
\mathrm{~L}(C)=0.0000\end{array}$ & -0.9738 & 0.0000 \\
\hline & & Improvement & $\operatorname{Bel}(\mathrm{A})=0.4545 \quad \operatorname{Bel}(\mathrm{B})=0.3719 \operatorname{Bel}(\mathrm{C})=0.1735$ & $A / A$ & $\begin{array}{l}\mathrm{L}(A)=0.0000 \\
\mathrm{~L}(B)=0.0000 \\
\mathrm{~L}(C)=0.0000\end{array}$ & 0.0826 & 0.0064 \\
\hline \multirow{7}{*}{$\begin{array}{l}\text { General } \\
\text { conflict } \\
\text { (example } \\
5)\end{array}$} & \multirow[t]{7}{*}{$\begin{array}{c}S_{1}^{\prime}, S_{2}^{\prime} \\
S_{3}^{\prime}\end{array}$} & D-S theory & $\operatorname{Bel}(\mathrm{A})=0.9313 \quad \operatorname{Bel}(\mathrm{B})=0.0090 \operatorname{Bel}(\mathrm{C})=0.0597$ & $A / A$ & $\begin{array}{l}\mathrm{L}(A)=0.0000 \\
\mathrm{~L}(B)=0.0000 \\
\mathrm{~L}(C)=0.0000\end{array}$ & 0.9716 & 0.0000 \\
\hline & & Murphy & $\operatorname{Bel}(\mathrm{A})=0.9287 \quad \operatorname{Bel}(\mathrm{B})=0.0094 \quad \operatorname{Bel}(\mathrm{C})=0.0619$ & $A / A$ & $\begin{array}{l}\mathrm{L}(A)=0.0000 \\
\mathrm{~L}(B)=0.0000 \\
\mathrm{~L}(C)=0.0000\end{array}$ & 0.8668 & 0.0000 \\
\hline & & Deng & $\operatorname{Bel}(\mathrm{A})=0.9751 \quad \operatorname{Bel}(\mathrm{B})=0.0100 \operatorname{Bel}(\mathrm{C})=0.0149$ & $A / A$ & $\begin{array}{l}\mathrm{L}(A)=0.0000 \\
\mathrm{~L}(B)=0.0000 \\
\mathrm{~L}(C)=0.0000\end{array}$ & 0.9602 & 0.0000 \\
\hline & & Yager & $\operatorname{Bel}(\mathrm{A})=0.2340 \quad \operatorname{Bel}(\mathrm{B})=0.0023 \operatorname{Bel}(\mathrm{C})=0.0150$ & Unknown/A & $\begin{array}{l}\mathrm{L}(A)=0.7488 \\
\mathrm{~L}(B)=0.7488 \\
\mathrm{~L}(C)=0.7488\end{array}$ & 0.2190 & 0.7488 \\
\hline & & Dubois & $\operatorname{Bel}(\mathrm{A})=0.5160 \quad \operatorname{Bel}(\mathrm{B})=0.0278 \operatorname{Bel}(\mathrm{C})=0.1200$ & $A / A$ & $\begin{array}{l}\mathrm{L}(A)=0.3245 \\
\mathrm{~L}(B)=0.1893 \\
\mathrm{~L}(C)=0.2838\end{array}$ & 0.3960 & 0.1250 \\
\hline & & Smets & $\begin{array}{ll}\operatorname{Bel}(\mathrm{A})=0.2340 & \operatorname{Bel}(\mathrm{B})=0.0023 \\
\operatorname{Bel}(\mathrm{C})=0.0150 & \operatorname{Bel}(\varnothing)=0.7488\end{array}$ & Unknown/A & $\begin{array}{l}\mathrm{L}(A)=0.0000 \\
\mathrm{~L}(B)=0.0000 \\
\mathrm{~L}(C)=0.0000\end{array}$ & -0.5148 & 0.0000 \\
\hline & & Improvement & $\operatorname{Bel}(\mathrm{A})=0.9313 \operatorname{Bel}(\mathrm{B})=0.0090 \operatorname{Bel}(\mathrm{C})=0.0597$ & $A / A$ & $\begin{array}{l}\mathrm{L}(A)=0.0000 \\
\mathrm{~L}(B)=0.0000 \\
\mathrm{~L}(C)=0.0000\end{array}$ & 0.9716 & 0.0000 \\
\hline \multirow{5}{*}{$\begin{array}{l}\text { General } \\
\text { conflict } \\
\text { (example } \\
6)\end{array}$} & \multirow[t]{5}{*}{$\begin{array}{c}E_{1}^{\prime}, E_{2}^{\prime} \\
\quad E_{3}^{\prime}\end{array}$} & D-S theory & $\begin{array}{l}\operatorname{Bel}\left(\pi_{1}\right)=0.6731 \operatorname{Bel}\left(\pi_{2}\right)=0.3205 \\
\quad \operatorname{Bel}\left(\pi_{3}\right)=0.0064\end{array}$ & $\pi_{1} / \pi_{1}$ & $\begin{array}{l}\mathrm{L}\left(\pi_{1}\right)=0.0000 \\
\mathrm{~L}\left(\pi_{2}\right)=0.0000 \\
\mathrm{~L}\left(\pi_{3}\right)=0.0000\end{array}$ & 0.3526 & 0.0000 \\
\hline & & Murphy & $\begin{array}{l}\operatorname{Bel}\left(\pi_{1}\right)=0.6834 \\
\quad \operatorname{Bel}\left(\pi_{2}\right)=0.3079 \operatorname{Bel}\left(\pi_{3}\right)=0.0870\end{array}$ & $\pi_{1} / \pi_{1}$ & $\begin{array}{l}\mathrm{L}\left(\pi_{1}\right)=0.0000 \\
\mathrm{~L}\left(\pi_{2}\right)=0.0000 \\
\mathrm{~L}\left(\pi_{3}\right)=0.0000\end{array}$ & 0.3755 & 0.0000 \\
\hline & & Deng & $\begin{array}{l}\operatorname{Bel}\left(\pi_{1}\right)=0.6817 \\
\qquad \operatorname{Bel}\left(\pi_{2}\right)=0.3097 \operatorname{Bel}\left(\pi_{3}\right)=0.0086\end{array}$ & $\pi_{1} / \pi_{1}$ & $\begin{array}{l}\mathrm{L}\left(\pi_{1}\right)=0.0000 \\
\mathrm{~L}\left(\pi_{2}\right)=0.0000 \\
\mathrm{~L}\left(\pi_{3}\right)=0.0000\end{array}$ & 0.3720 & 0.0000 \\
\hline & & Yager & $\begin{array}{l}\operatorname{Bel}\left(\pi_{1}\right)=0.1050 \\
\quad \operatorname{Bel}\left(\pi_{2}\right)=0.0500 \operatorname{Bel}\left(\pi_{3}\right)=0.0010\end{array}$ & Unknown $/ \pi_{1}$ & $\begin{array}{l}\mathrm{L}\left(\pi_{1}\right)=0.8440 \\
\mathrm{~L}\left(\pi_{2}\right)=0.8440 \\
\mathrm{~L}\left(\pi_{3}\right)=0.8440\end{array}$ & 0.0550 & 0.8440 \\
\hline & & Dubois & $\operatorname{Bel}\left(\pi_{1}\right)=0.3950 \operatorname{Bel}\left(\pi_{2}\right)=0.2500 \operatorname{Bel}\left(\pi_{3}\right)=0.0240$ & $\pi_{1} / \pi_{1}$ & $\begin{array}{l}\mathrm{L}\left(\pi_{1}\right)=0.3145 \\
\mathrm{~L}\left(\pi_{2}\right)=0.3050 \\
\mathrm{~L}\left(\pi_{3}\right)=0.1845\end{array}$ & 0.3710 & 0.142 \\
\hline
\end{tabular}


Table 3 (continued)

\begin{tabular}{|c|c|c|c|c|c|c|}
\hline $\begin{array}{l}\text { Types of high Evidence } \\
\text { conflict }\end{array}$ & Methods & Belief function of the target to be identified & $\begin{array}{l}\text { Identified } \\
\text { target/real } \\
\text { target }\end{array}$ & $\begin{array}{l}\text { Uncertainty interval } \\
\text { value }\end{array}$ & $\mathrm{D}$ value & $\begin{array}{l}\text { The } \\
\text { unknown } \\
\text { degree }\end{array}$ \\
\hline & Smets & $\begin{array}{cc}\operatorname{Bel}\left(\pi_{1}\right)=0.1050 & \operatorname{Bel}\left(\pi_{2}\right)=0.0500 \\
\operatorname{Bel}\left(\pi_{3}\right)=0.0010 & \operatorname{Bel}(\varnothing)=0.9433\end{array}$ & Unknown $/ \pi_{1}$ & $\begin{array}{l}\mathrm{L}\left(\pi_{1}\right)=0.0000 \\
\mathrm{~L}\left(\pi_{2}\right)=0.0000 \\
\mathrm{~L}\left(\pi_{3}\right)=0.0000\end{array}$ & -0.8383 & 0.0000 \\
\hline & Improvement & $\begin{array}{l}\operatorname{Bel}\left(\pi_{1}\right)=0.6878 \quad \operatorname{Bel}\left(\pi_{2}\right)=0.2957 \\
\operatorname{Bel}\left(\pi_{3}\right)=0.0155\end{array}$ & $\pi_{1} / \pi_{1}$ & $\begin{array}{l}\mathrm{L}\left(\pi_{1}\right)=0.0010 \\
\mathrm{~L}\left(\pi_{2}\right)=0.0010 \\
\mathrm{~L}\left(F_{3}\right)=0.0010\end{array}$ & 0.3921 & 0.0010 \\
\hline
\end{tabular}

obtained by the proposed method and Deng's method are higher than those obtained by Murphy's method. However, according to Table 4 in the appendix, Deng's method cannot identify the real target in example 6 . The proposed method and Murphy's method are able to obtain the real targets in all the examples. The other methods cannot identify the correct results insome examples above.

Based on the above analysis, it can be seen that the ability of the proposed method to identify real targets is better than that of other methods. In addition, there are five pieces of evidence in examples 3 and 5, but the other examples have only four pieces of evidence. Therefore, in terms of the five pieces of evidence in examples 3 and 5, the fusion results of various methods are not analysed in detail. The fusion results are shown in Table 5 in the appendix.

From Fig. 4, because the belief values of the real targets obtained by D-S theory, Yager's method, and Dubois' method are 0 in example 2 when fusing two pieces of evidence, the uncertain interval values of the targets to be identified obtained by these methods are 1 , while the uncertain interval values of the targets to be identified obtained by the other methods are very low in all the examples. On the basis of correctly identifying the real target, combining Figs. 5 and 6 , it can be seen that the uncertain interval values of the targets to be identified obtained by Yager's and Dubois' methods are much higher than those obtained by other methods, while the uncertain interval values of the targets to be identified obtained by the proposed method and other methods are zero or close to zero. As introduced in section 3, the greater the value is, the greater the uncertainty of the identified target, which will increase the risk of incorrectly identifying the target. It shows that the performance of Yager's and Dubois' methods are worse than the proposed method, Murphy's method and Deng's method, while there is no significant difference in the uncertain interval value obtained by the three methods.

Negative D values indicate that the methods cannot identify the real targets in these examples. The greater the $\mathrm{D}$ value, the more likely it is to obtain the real target, so it can be seen that all the methods fail to obtain the real target in example 4 when fusing two pieces of evidence. On the basis of correctly identifying the real target, the following conclusions can be drawn from Fig. 7: (1) D values obtained by all the methods are equal to or less than 0 in examples 1,2 , and 4; and (2) the D value obtained by D-S theory is the highest $(0.9780)$, followed by the proposed method (0.9440) in example 3; and (3) D values obtained by the proposed method are the highest in example 5 and example 6 .

The following conclusions can be drawn from Fig. 8: (1) the D values obtained by the proposed method and Deng's method are higher than those obtained by other methods in examples 1, 2, 3, and 6; and (2) the D value obtained by the proposed method is lower than those obtained by Dubois' method and Deng's method in example 4; and (3) the D value obtained by Deng's method is lower than those obtained by the proposed method and D-S theory in example 5; and (4) the difference between the $\mathrm{D}$ values obtained by the proposed method and D values obtained by Deng's method various across examples, which makes it difficult to evaluate the performance of these two methods.

It can be seen from Fig. 9 that the following conclusions can be drawn: (1) the D values obtained by the proposed method are higher than those obtained by other methods in example 3 and 6; and (2) the D values obtained by the proposed method and Deng's method are higher than those obtained by other methods in example $1,2,4$, while the $\mathrm{D}$ values obtained by Deng's method are higher than those obtained by the proposed method in these examples; and (3) in example 5, there is no significant difference in the $\mathrm{D}$ values obtained by the proposed method, D-S theory, Deng's method, and Murphy's method, and the D values obtained by them are $0.9344,0.9344,0.9380$ and 0.9380 , respectively.

Through the comparative analysis of $\mathrm{D}$ values obtained by different methods, it can be seen that the performance of the proposed method and Deng's method is better than other methods, while the performance of the two methods various across examples.

In the bubble chart, the bubble represents the unknown degree of the fusion results. The larger the bubble is, the greater the unknown degree of the fusion results. From Figs. 10, 11 and 12, combined with Table 2 to Table 4 in the appendix, the following conclusions can be drawn: (1) The unknown degree of fusion results obtained by the proposed method are either 0 
Table 4 Fusion results of various methods for different examples under four pieces of evidence

Types of high evidence Methods Belief function of the target to be identified

$\begin{array}{lll}\text { Identified } & \text { Uncertainty interval } & \mathrm{D} \text { value } \\ \text { target/true } & \text { value } & \text { un }\end{array}$ target conflict

unknown degree

\begin{tabular}{|c|c|c|c|c|c|c|c|c|c|}
\hline \multirow[t]{7}{*}{$\begin{array}{c}\text { "Total Trust" } \\
\text { conflict } \\
\text { (example 1) }\end{array}$} & $\begin{array}{l}\mathrm{S}_{1}, \mathrm{~S}_{2} \\
\mathrm{~S}_{3}, \mathrm{~S}_{4}\end{array}$ & D-S theory & $\operatorname{Bel}\left(\theta_{1}\right)=0.0000$ & $\operatorname{Bel}\left(\theta_{2}\right)=1.0000$ & $\operatorname{Bel}\left(\theta_{3}\right)=0.0000$ & $\theta_{2} / \theta_{3}$ & $\begin{array}{l}\mathrm{L}\left(\theta_{1}\right)=0.0000 \\
\mathrm{~L}\left(\theta_{2}\right)=0.0000 \\
\mathrm{~L}\left(\theta_{3}\right)=0.0000\end{array}$ & -1.0000 & 0.0000 \\
\hline & & Murphy & $\operatorname{Bel}\left(\theta_{1}\right)=0.0422$ & $\operatorname{Bel}\left(\theta_{2}\right)=0.0018$ & $\operatorname{Bel}\left(\theta_{3}\right)=0.9560$ & $\theta_{3} / \theta_{3}$ & $\begin{array}{l}\mathrm{L}\left(\theta_{1}\right)=0.0000 \\
\mathrm{~L}\left(\theta_{2}\right)=0.0000 \\
\mathrm{~L}\left(\theta_{2}\right)=0.0000\end{array}$ & 0.9138 & 0.0000 \\
\hline & & Deng & $\operatorname{Bel}\left(\theta_{1}\right)=0.0013$ & $\operatorname{Bel}\left(\theta_{2}\right)=0.0011$ & $\operatorname{Bel}\left(\theta_{3}\right)=0.9976$ & $\theta_{3} / \theta_{3}$ & $\begin{array}{l}\mathrm{L}\left(\theta_{1}\right)=0.0000 \\
\mathrm{~L}\left(\theta_{2}\right)=0.0000 \\
\mathrm{~L}\left(\theta_{3}\right)=0.0000\end{array}$ & 0.9963 & 0.0000 \\
\hline & & Yager & $\operatorname{Bel}\left(\theta_{1}\right)=0.0000$ & $\operatorname{Bel}\left(\theta_{2}\right)=0.0002$ & $\operatorname{Bel}\left(\theta_{3}\right)=0.0000$ & Unknown/ $\theta_{3}$ & $\begin{array}{l}\mathrm{L}\left(\theta_{1}\right)=0.9998 \\
\mathrm{~L}\left(\theta_{2}\right)=0.9998 \\
\mathrm{~L}\left(\theta_{3}\right)=0.9998\end{array}$ & -0.0002 & 0.9998 \\
\hline & & Dubois & $\operatorname{Bel}\left(\theta_{1}\right)=0.0289$ & $\operatorname{Bel}\left(\theta_{2}\right)=0.0353$ & $\operatorname{Bel}\left(\theta_{3}\right)=0.6604$ & $\theta_{3} / \theta_{3}$ & $\begin{array}{l}\mathrm{L}\left(\theta_{1}\right)=0.1592 \\
\mathrm{~L}\left(\theta_{2}\right)=0.1405 \\
\mathrm{~L}\left(\theta_{3}\right)=0.2591\end{array}$ & -0.6315 & 0.0015 \\
\hline & & Smets & $\begin{array}{r}\operatorname{Bel}\left(\theta_{1}\right)=0.0000 \\
\operatorname{Bel}(\varnothing)=0.99\end{array}$ & $\begin{array}{l}\operatorname{Bel}\left(\theta_{2}\right)=0.0002 \\
88\end{array}$ & $\operatorname{Bel}\left(\theta_{3}\right)=0.0000$ & Unknown/ $\theta_{3}$ & $\begin{array}{l}\mathrm{L}\left(\theta_{1}\right)=0.0000 \\
\mathrm{~L}\left(\theta_{2}\right)=0.0000 \\
\mathrm{~L}\left(\theta_{3}\right)=0.0000\end{array}$ & -0.9988 & 0.0000 \\
\hline & & Improvement & $\operatorname{Bel}\left(\theta_{1}\right)=0.0033$ & $\operatorname{Bel}\left(\theta_{2}\right)=0.0091$ & $\operatorname{Bel}\left(\theta_{3}\right)=0.9878$ & $\theta_{3} / \theta_{3}$ & $\begin{array}{l}\mathrm{L}\left(\theta_{1}\right)=0.0001 \\
\mathrm{~L}\left(\theta_{2}\right)=0.0001 \\
\mathrm{~L}\left(\theta_{3}\right)=0.0001\end{array}$ & 0.9787 & 0.0001 \\
\hline \multirow{7}{*}{$\begin{array}{l}\text { Complete conflict } \\
\text { (example 2) }\end{array}$} & $E_{1}, E_{2}$ & D-S theory & & $\sim$ & & $/ A$ & $\sim$ & $\sim$ & $\sim$ \\
\hline & $\mathrm{E}_{3}, \mathrm{E}_{4}$ & Murphy & $\operatorname{Bel}(\mathrm{A})=0.9566$ & $\operatorname{Bel}(\mathrm{B})=0.0434$ & $\operatorname{Bel}(\mathrm{C})=0.0000$ & $A / A$ & $\begin{array}{l}\mathrm{L}(A)=0.0000 \\
\mathrm{~L}(B)=0.0000 \\
\mathrm{~L}(C)=0.0000\end{array}$ & 0.9132 & 0.0000 \\
\hline & & Deng & $\operatorname{Bel}(\mathrm{A})=0.9995$ & $\operatorname{Bel}(\mathrm{B})=0.0004$ & $\operatorname{Bel}(\mathrm{C})=0.0000$ & $A / A$ & $\begin{array}{l}\mathrm{L}(A)=0.0000 \\
\mathrm{~L}(B)=0.0000 \\
\mathrm{~L}(C)=0.0000\end{array}$ & 0.9991 & 0.0000 \\
\hline & & Yager & $\operatorname{Bel}(\mathrm{A})=0.0000$ & $\operatorname{Bel}(\mathrm{B})=0.0000$ & $\operatorname{Bel}(\mathrm{C})=0.0000$ & Unknown/A & $\begin{array}{l}\mathrm{L}(A)=1.0000 \\
\mathrm{~L}(B)=1.0000 \\
\mathrm{~L}(C)=1.0000\end{array}$ & 0.0000 & 0.0000 \\
\hline & & Dubois & $\operatorname{Bel}(\mathrm{A})=0.7200$ & $\operatorname{Bel}(\mathrm{B})=0.0200$ & $\operatorname{Bel}(\mathrm{C})=0.0100$ & $A / A$ & $\begin{array}{l}\mathrm{L}(A)=0.2400 \\
\mathrm{~L}(B)=0.1700 \\
\mathrm{~L}(C)=0.0900\end{array}$ & 0.7000 & 0.0000 \\
\hline & & Smets & $\begin{array}{l}\operatorname{Bel}(\mathrm{A})=0.0000 \\
\operatorname{Bel}(\mathrm{C})=0.0000\end{array}$ & $\begin{array}{l}\operatorname{Bel}(\mathrm{B})=0.0000 \\
\operatorname{Bel}(\varnothing)=1.0000\end{array}$ & & Unknown/A & $\begin{array}{l}\mathrm{L}(A)=0.0000 \\
\mathrm{~L}(B)=0.0000 \\
\mathrm{~L}(C)=0.0000\end{array}$ & -1.0000 & 0.0000 \\
\hline & & Improvement & $\operatorname{Bel}(\mathrm{A})=0.9970$ & $\operatorname{Bel}(\mathrm{B})=0.0022$ & $\operatorname{Bel}(\mathrm{C})=0.0007$ & $A / A$ & $\begin{array}{l}\mathrm{L}(A)=0.0000 \\
\mathrm{~L}(B)=0.0000 \\
\mathrm{~L}(C)=0.0000\end{array}$ & 0.9948 & 0.0000 \\
\hline \multirow[t]{7}{*}{$\begin{array}{l}\text { "One Ballot } \\
\text { Veto" conflict } \\
\text { (example 3) }\end{array}$} & $\begin{array}{c}\mathrm{M}_{1}, \mathrm{M}_{2} \\
\mathrm{M}_{3} \\
\mathrm{M}_{4}\end{array}$ & D-S theory & $\operatorname{Bel}\left(w_{1}\right)=0.0000$ & $\operatorname{Bel}\left(w_{2}\right)=0.8571$ & $\operatorname{Bel}\left(\mathrm{w}_{3}\right)=0.1429$ & $w_{2} / w_{1}$ & $\begin{array}{l}\mathrm{L}\left(w_{1}\right)=0.0000 \\
\mathrm{~L}\left(w_{2}\right)=0.0000 \\
\mathrm{~L}\left(\mathrm{w}_{3}\right)=0.0000\end{array}$ & -0.7142 & 0.0000 \\
\hline & & Murphy & $\operatorname{Bel}\left(w_{1}\right)=0.6756$ & $\operatorname{Bel}\left(w_{2}\right)=0.3208$ & $\operatorname{Bel}\left(\mathrm{w}_{3}\right)=0.0007$ & $w_{1} / w_{1}$ & $\begin{array}{l}\mathrm{L}\left(w_{1}\right)=0.0007 \\
\mathrm{~L}\left(w_{2}\right)=0.0009 \\
\mathrm{~L}\left(\mathrm{w}_{3}\right)=0.0002\end{array}$ & 0.3548 & 0.0000 \\
\hline & & Deng & $\operatorname{Bel}\left(w_{1}\right)=0.7484$ & $\operatorname{Bel}\left(w_{2}\right)=0.2479$ & $\operatorname{Bel}\left(\mathrm{w}_{3}\right)=0.0022$ & $w_{1} / w_{1}$ & $\begin{array}{l}\mathrm{L}\left(w_{1}\right)=0.0013 \\
\mathrm{~L}\left(w_{2}\right)=0.0014 \\
\mathrm{~L}\left(\mathrm{w}_{3}\right)=0.0002\end{array}$ & 0.5005 & 0.0000 \\
\hline & & Yager & $\operatorname{Bel}\left(w_{1}\right)=0.0000$ & $\operatorname{Bel}\left(w_{2}\right)=0.0022$ & $\operatorname{Bel}\left(\mathrm{w}_{3}\right)=0.0004$ & Unknown/ $w_{1}$ & $\begin{array}{l}\mathrm{L}\left(w_{1}\right)=0.9975 \\
\mathrm{~L}\left(w_{2}\right)=0.9975 \\
\mathrm{~L}\left(\mathrm{w}_{3}\right)=0.9975\end{array}$ & -0.0022 & 0.9975 \\
\hline & & Dubois & $\operatorname{Bel}\left(w_{1}\right)=0.4063$ & $\operatorname{Bel}\left(w_{2}\right)=0.3565$ & $\operatorname{Bel}\left(w_{3}\right)=0.0271$ & $w_{1} / w_{1}$ & $\begin{array}{l}\mathrm{L}\left(w_{1}\right)=0.1803 \\
\mathrm{~L}\left(w_{2}\right)=0.2084 \\
\mathrm{~L}\left(\mathrm{w}_{3}\right)=0.1193\end{array}$ & 0.0499 & 0.0875 \\
\hline & & Smets & $\begin{array}{l}\operatorname{Bel}\left(w_{1}\right) \\
\operatorname{Bel}\left(w_{3}\right)\end{array}$ & $\begin{array}{l}=0.0000 \quad \operatorname{Bel}(x) \\
=0.0004 \quad \operatorname{Bel}(\ell\end{array}$ & $\begin{array}{l}\left(w_{2}\right)=0.0022 \\
\varnothing)=0.9975\end{array}$ & Unknown $/ w_{1}$ & $\begin{array}{l}\mathrm{L}\left(w_{1}\right)=0.0000 \\
\mathrm{~L}\left(w_{2}\right)=0.0000 \\
\mathrm{~L}\left(\mathrm{w}_{3}\right)=0.0000\end{array}$ & -0.9975 & 0.0000 \\
\hline & & Improvement & $\operatorname{Bel}\left(w_{1}\right)=0.8356$ & $\operatorname{Bel}\left(w_{2}\right)=0.1485$ & $\operatorname{Bel}\left(w_{3}\right)=0.0108$ & $w_{1} / w_{1}$ & $\begin{array}{l}\mathrm{L}\left(w_{1}\right)=0.0028 \\
\mathrm{~L}\left(w_{2}\right)=0.0043 \\
\mathrm{~L}\left(\mathrm{w}_{3}\right)=0.0036\end{array}$ & 0.6871 & 0.0006 \\
\hline
\end{tabular}


Table 4 (continued)

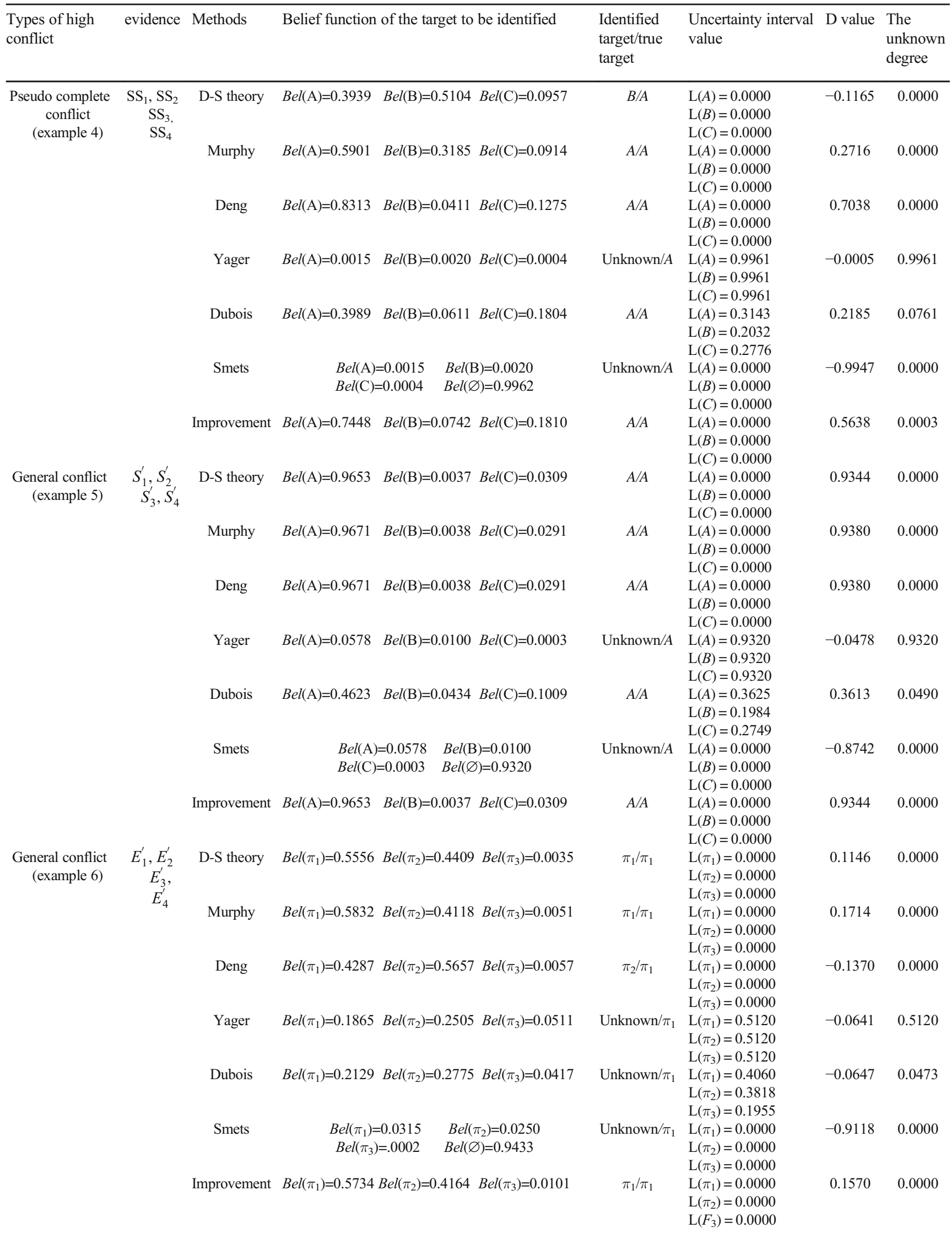


or close to 0 in the fusion of different amounts of evidence in the examples except for example 2 in Fig. 10 (0.1429). (2) Dempster's rule of combination cannot be applied in example 2 because the normalized coefficient $1 / 1-k$ is 0 . Any useful information cannot be obtained based on D-S theory, so the unknown degree in example 2 is 1.0000 , while the unknown degree of the fusion results obtained by D-S theory is 0 in the other examples. (3) The unknown degree of the fusion results obtained by Deng's method and Murphy's method are either 0 or close to 0 in the above examples. (4) The unknown degree of the fusion results obtained by Dubois' method and Yager's method are obviously higher than those obtained by other methods in the fusion of different amounts of evidence in many examples, although the unknown degree of the fusion results obtained by Smets' method are 0 in the above examples, the method cannot identify the real targets in the examples except for example 3 in Fig. 8.

According to the unknown degree of the fusion results for different examples, the performance of Deng's method and Murphy's method is best, followed by the proposed method and D-S theory. The performances of Dubois' method, Yager's method, and Smets' method are worse than those of the other methods.

From the perspective of various indicators, the proposed method and Deng's method are superior to the other methods, while Deng's method is slightly better than the proposed method. However, the proposed method can identify the real targets that Deng's method cannot identify in a certain example, for example, in Fig. 9, Deng's method fails to identify the real target in example 6 , while the proposed method is able to obtain the right result. In other examples, the two methods have the same ability to identify the real target.

\subsection{Application}

In this section, four real cases are used to further verify the effectiveness of the proposed method.

\subsubsection{Fault diagnosis based on multisource information fusion}

Case 1 Suppose that the frame of discernment $(\Theta)$ consists of three different faults $\left\{F_{1}, F_{2}, F_{3}\right\}$. The set of sensors given by $\mathrm{S}=\{\mathrm{S} 1, \mathrm{~S} 2, \mathrm{~S} 3\}$ are positioned on different places to gather the reports [3]. The BPAs of the sensors are listed as follows:

$$
\begin{aligned}
\mathrm{S} 1: & m_{1}\left(F_{1}\right)=0.60 \quad m_{1}\left(F_{2}\right)=0.10 \\
& m_{1}\left(F_{2}, F_{3}\right)=0.10 \quad m_{1}\left(F_{1}, F_{2}, F_{3}\right)=0.20 \\
\mathrm{~S} 2: & m_{2}\left(F_{1}\right)=0.05 \quad m_{2}\left(F_{2}\right)=0.80 \\
& m_{2}\left(F_{2}, F_{3}\right)=0.05 \quad m_{2}\left(F_{1}, F_{2}, F_{3}\right)=0.10 \\
\mathrm{~S} 3: & m_{3}\left(F_{1}\right)=0.70 \quad m_{3}\left(F_{2}\right)=0.10 \\
& m_{3}\left(F_{2}, F_{3}\right)=0.10 \quad m_{3}\left(F_{1}, F_{2}, F_{3}\right)=0.10
\end{aligned}
$$

Based on the information provided above, sensors S1 and S3 both support $F_{1}$ with the maximum support degree, while sensor $\mathrm{S} 2$ strongly supports $F_{2}$. This indicates that there is a high conflict between sensors S1 and S3 and sensor S2. The combination results obtained by several methods are shown in Table 6.

From Table 6, it can be seen that the fault judged by D-S evidence theory is an incorrect result because the real type of fault is $F_{1}$. Smets' method assigns conflict information to the empty set so that the belief function of the faults to be identified is too small to support any type of fault. Yager's method assigns conflict information to focal element $\Theta$. This causes the belief function of $\Theta$ to be much larger than that of any fault type, so it is unable to determine which fault is real. The proposed method is able to diagnose the fault type $F_{1}$, which is consistent with Murphy's method, Deng's method and Dubois' method, and the belief function of fault $F_{1}$ obtained by the proposed method is greater than that of Murphy's method and Dubois' method. Based on these four indicators, the performance of Deng's method is the best, followed by that of the proposed method.

\subsubsection{Type recognition based on multisource information fusion}

Case 2 In the Iris dataset, there were three species of iris flowers (Setosa, Versicolor, and Virginica). Three species of iris flowers form a frame of discernment $\Theta=\{S e, V e, V i\}$. Given data collected from Iris data, shown as $\{5.3 \mathrm{~cm}, 3.5 \mathrm{~cm}, 1.3 \mathrm{~cm}$, $0.2 \mathrm{~cm}\}$. The data represent four attributes of iris flowers: sepal length (SL), sepal width (SW), petal length (PL), and petal width $(P W)$. The data above belong to "Setosa". The four attributes that are modelled as BPAs are shown in Table 7 [20].

Based on the data above, it can be seen that the information between the four attributes has good consistency, and all attributes identify the target as Se. The various methods are used to conduct multi-attribute information fusion, and the fusion results are shown in Table 8.

As seen from Table 8, except for Smets' method and Yager's method, the other methods can correctly identify the type of flowers (Se). Although Dubois' method identifies the real target, the indicators obtained by this method are inferior to those obtained by the other three methods. D-S theory, Murphy's method, Deng's method, and the proposed method can obtain ideal fusion results. According to these four indicators, the proposed method and D-S theory outperform the other methods, while there is no difference in performance between the two methods.

To verify the anti-interference performance of the proposed method, the information of the attribute SW is assumed to be interfered with, and the corresponding BPAs are listed as follows [23]: 
Table 5 Fusion results of various methods for different examples under five pieces of evidence

\begin{tabular}{|c|c|c|c|c|c|c|c|}
\hline $\begin{array}{l}\text { Types of high } \\
\text { conflict }\end{array}$ & Evidence & Methods & Belief function of the target to be identified & $\begin{array}{l}\text { Identified } \\
\text { target /real } \\
\text { target }\end{array}$ & $\begin{array}{l}\text { Uncertainty } \\
\text { interval value }\end{array}$ & $\mathrm{D}$ value & $\begin{array}{c}\text { The unknown } \\
\text { degree }\end{array}$ \\
\hline \multirow{7}{*}{$\begin{array}{l}\text { "One Ballot } \\
\text { Veto" } \\
\text { conflict } \\
\text { (example 3) }\end{array}$} & \multirow[t]{7}{*}{$\begin{array}{l}\mathrm{M}_{1}, \mathrm{M}_{2} \\
\mathrm{M}_{3}, \mathrm{M}_{4} \\
\mathrm{M}_{5}\end{array}$} & D-S theory & $\begin{array}{l}\operatorname{Bel}\left(w_{1}\right)=0.0000 \operatorname{Bel}\left(w_{2}\right)=0.9091 \\
\quad \operatorname{Bel}\left(\mathrm{w}_{3}\right)=0.0000\end{array}$ & $w_{2} / w_{1}$ & $\begin{array}{l}\mathrm{L}\left(w_{1}\right)=0.0000 \\
\mathrm{~L}\left(w_{2}\right)=0.0000 \\
\mathrm{~L}\left(\mathrm{w}_{3}\right)=0.0000\end{array}$ & -0.9091 & 0.0000 \\
\hline & & Murphy & $\begin{array}{l}\operatorname{Bel}\left(w_{1}\right)=0.7480 \operatorname{Bel}\left(w_{2}\right)=0.2500 \\
\quad \operatorname{Bel}\left(\mathrm{w}_{3}\right)=0.0016\end{array}$ & $w_{1} / w_{1}$ & $\begin{array}{l}\mathrm{L}\left(w_{1}\right)=0.0003 \\
\mathrm{~L}\left(w_{2}\right)=0.0004 \\
\mathrm{~L}\left(\mathrm{w}_{3}\right)=0.0001\end{array}$ & 0.5980 & 0.0000 \\
\hline & & Deng & $\begin{array}{l}\operatorname{Bel}\left(w_{1}\right)=0.8129 \operatorname{Bel}\left(w_{2}\right)=0.1850 \\
\quad \operatorname{Bel}\left(\mathrm{w}_{3}\right)=0.0015\end{array}$ & $w_{1} / w_{1}$ & $\begin{array}{l}\mathrm{L}\left(w_{1}\right)=0.0005 \\
\mathrm{~L}\left(w_{2}\right)=0.0006 \\
\mathrm{~L}\left(\mathrm{w}_{3}\right)=0.0001\end{array}$ & 0.6279 & 0.0000 \\
\hline & & Yager & $\begin{array}{l}\operatorname{Bel}\left(w_{1}\right)=0.3284 \operatorname{Bel}\left(w_{2}\right)=0.2045 \\
\operatorname{Bel}\left(\mathrm{w}_{3}\right)=0.0339\end{array}$ & Unknown $/ w_{1}$ & $\begin{array}{l}\mathrm{L}\left(w_{1}\right)=0.4043 \\
\mathrm{~L}\left(w_{2}\right)=0.4206 \\
\mathrm{~L}\left(\mathrm{w}_{3}\right)=0.4206\end{array}$ & 0.1239 & 0.3793 \\
\hline & & Dubois & $\begin{array}{l}\operatorname{Bel}\left(w_{1}\right)=0.3658 \operatorname{Bel}\left(w_{2}\right)=0.2320 \\
\quad \operatorname{Bel}\left(w_{3}\right)=0.0113\end{array}$ & $w_{1} / w_{1}$ & $\begin{array}{l}\mathrm{L}\left(w_{1}\right)=0.3709 \\
\mathrm{~L}\left(w_{2}\right)=0.3710 \\
\mathrm{~L}\left(\mathrm{w}_{3}\right)=0.1403\end{array}$ & 0.1338 & 0.1001 \\
\hline & & Smets & $\begin{array}{c}\operatorname{Bel}\left(w_{1}\right)=0.0000 \quad \operatorname{Bel}\left(w_{2}\right)=0.0011 \\
\operatorname{Bel}\left(\mathrm{w}_{3}\right)=0.0001 \quad \operatorname{Bel}(\varnothing)=0.9988\end{array}$ & Unknown $/ w_{1}$ & $\begin{array}{l}\mathrm{L}\left(w_{1}\right)=0.0000 \\
\mathrm{~L}\left(w_{2}\right)=0.0000 \\
\mathrm{~L}\left(\mathrm{w}_{3}\right)=0.0000\end{array}$ & -0.9988 & 0.0000 \\
\hline & & Improvement & $\begin{array}{l}\operatorname{Bel}\left(w_{1}\right)=0.8292 \quad \operatorname{Bel}\left(w_{2}\right)=0.1627 \\
\quad \operatorname{Bel}\left(\mathrm{w}_{3}\right)=0.0067\end{array}$ & $w_{1} / w_{1}$ & $\begin{array}{l}\mathrm{L}\left(w_{1}\right)=0.0007 \\
\mathrm{~L}\left(w_{2}\right)=0.0012 \\
\mathrm{~L}\left(\mathrm{w}_{3}\right)=0.0010\end{array}$ & 0.6665 & 0.0001 \\
\hline \multirow[t]{7}{*}{$\begin{array}{l}\text { General } \\
\text { conflict } \\
\text { (example 5) }\end{array}$} & \multirow[t]{7}{*}{$\underset{S_{1}^{\prime}, S_{2}^{\prime} S_{3}^{\prime}}{S_{4}^{\prime}}$} & D-S theory & $\begin{array}{l}\operatorname{Bel}(\mathrm{A})=0.9851 \quad \operatorname{Bel}(\mathrm{B})=0.0006 \\
\operatorname{Bel}(\mathrm{C})=0.0144\end{array}$ & $A / A$ & $\begin{array}{l}\mathrm{L}(A)=0.0000 \\
\mathrm{~L}(B)=0.0000 \\
\mathrm{~L}(C)=0.0000\end{array}$ & 0.9671 & 0.0000 \\
\hline & & Murphy & $\begin{array}{l}\operatorname{Bel}(\mathrm{A})=0.9843 \quad \operatorname{Bel}(\mathrm{B})=0.0007 \\
\operatorname{Bel}(\mathrm{C})=0.0150\end{array}$ & $A / A$ & $\begin{array}{l}\mathrm{L}(A)=0.0000 \\
\mathrm{~L}(B)=0.0000 \\
\mathrm{~L}(C)=0.0000\end{array}$ & 0.9693 & 0.0000 \\
\hline & & Deng & $\begin{array}{l}\operatorname{Bel}(\mathrm{A})=0.9877 \quad \operatorname{Bel}(\mathrm{B})=0.0007 \\
\operatorname{Bel}(\mathrm{C})=0.0152\end{array}$ & $A / A$ & $\begin{array}{l}\mathrm{L}(A)=0.0000 \\
\mathrm{~L}(B)=0.0000 \\
\mathrm{~L}(C)=0.0000\end{array}$ & 0.9725 & 0.0000 \\
\hline & & Yager & $\begin{array}{l}\operatorname{Bel}(\mathrm{A})=0.0347 \quad \operatorname{Bel}(\mathrm{B})=0.0010 \\
\operatorname{Bel}(\mathrm{C})=0.0001\end{array}$ & $A / A$ & $\begin{array}{l}\mathrm{L}(A)=0.9643 \\
\mathrm{~L}(B)=0.9643 \\
\mathrm{~L}(C)=0.9643\end{array}$ & 0.0337 & 0.9643 \\
\hline & & Dubois & $\begin{array}{l}\operatorname{Bel}(\mathrm{A})=0.5043 \quad \operatorname{Bel}(\mathrm{B})=0.0217 \\
\operatorname{Bel}(\mathrm{C})=0.1211\end{array}$ & $A / A$ & $\begin{array}{l}\mathrm{L}(A)=0.3323 \\
\mathrm{~L}(B)=0.1261 \\
\mathrm{~L}(C)=0.2846\end{array}$ & 0.3832 & 0.0375 \\
\hline & & Smets & $\begin{array}{ll}\operatorname{Bel}(\mathrm{A})=0.0772 & \operatorname{Bel}(\mathrm{B})=0.0000 \\
\operatorname{Bel}(\mathrm{C})=0.0011 & \operatorname{Bel}(\varnothing)=0.9216\end{array}$ & Unknown/A & $\begin{array}{l}\mathrm{L}(A)=0.0000 \\
\mathrm{~L}(B)=0.0000 \\
\mathrm{~L}(C)=0.0000\end{array}$ & -0.8444 & 0.0000 \\
\hline & & Improvement & $\begin{array}{l}\operatorname{Bel}(\mathrm{A})=0.9851 \quad \operatorname{Bel}(\mathrm{B})=0.0006 \\
\operatorname{Bel}(\mathrm{C})=0.0144\end{array}$ & $A / A$ & $\begin{array}{l}\mathrm{L}(A)=0.0000 \\
\mathrm{~L}(B)=0.0000 \\
\mathrm{~L}(C)=0.0000\end{array}$ & 0.9707 & 0.0000 \\
\hline
\end{tabular}

$S W^{\prime}: m_{s w}^{\prime}(\mathrm{Se})=0.0000, m_{s w}^{\prime}(\mathrm{Ve})=0.9900$ $m_{s w}^{\prime}(\mathrm{Vi})=0.0100, m_{s w}^{\prime}(\mathrm{Se}, \mathrm{Ve})=0.0000$

$m_{s w}^{\prime}(\mathrm{Se}, \mathrm{Vi})=0.0000, m_{s w}^{\prime}(\mathrm{Ve}, \mathrm{Vi})=0.0000, m_{s w}^{\prime}(\Theta)=0.0000$

When SW becomes an interference term, SW conflicts significantly with other attributes. The fusion results of different methods after interference are shown in Table 9.

From Table 9, D-S theory and Murphy's method classify the type of flower as versicolor (Ve) which is the wrong classification. Although $\operatorname{Bel}(\mathrm{Se})$ obtained by Yager's method is larger than $\operatorname{Bel}(\mathrm{Ve})$ and $\operatorname{Bel}(\mathrm{Vi})$ obtained by Yager's method, $\operatorname{Bel}(\mathrm{Se})(0.0213)$ is too small, and the unknown degree (0.9787) is far greater than $\operatorname{Bel}(\mathrm{Ve})$; therefore, the real type cannot be identified by Yager's method. The belief function of the empty set (0.9787) obtained by Smets' method is far greater than those of other recognition types obtained by Smets' method, so the fusion results cannot provide any useful information for identifying the type of flower. The other three methods can correctly identify the type of flower; however, $\mathrm{Bel}(\mathrm{Se})$ obtained by Dubois' method is smaller than that of the other two methods, which decreases the credibility of the identified type. The uncertainty interval value obtained by Dubois' 
Table 6 The comparison results between the proposed method and other methods

\begin{tabular}{|c|c|c|c|c|c|}
\hline Methods & Belief function of the target to be identified & $\begin{array}{l}\text { Identified target } \\
\text { /real target }\end{array}$ & $\begin{array}{l}\text { Uncertainty interval } \\
\text { value }\end{array}$ & $\mathrm{D}$ value & The unknown degree \\
\hline D-S theory & $\begin{array}{l}\operatorname{Bel}\left(F_{1}\right)=0.4519 \\
\operatorname{Bel}\left(F_{2}\right)=0.5048 \\
\operatorname{Bel}\left(F_{3}\right)=0.0000\end{array}$ & $F_{2} / F_{1}$ & $\begin{array}{l}\mathrm{L}\left(F_{1}\right)=0.0096 \\
\mathrm{~L}\left(F_{2}\right)=0.0433 \\
\mathrm{~L}\left(F_{3}\right)=0.0433\end{array}$ & -0.0529 & 0.0096 \\
\hline Murphy & $\begin{array}{l}\operatorname{Bel}\left(F_{1}\right)=0.5410 \\
\operatorname{Bel}\left(F_{2}\right)=0.4309 \\
\operatorname{Bel}\left(F_{3}\right)=0.0000\end{array}$ & $F_{1} / F_{1}$ & $\begin{array}{l}\mathrm{L}\left(F_{1}\right)=0.0065 \\
\mathrm{~L}\left(F_{2}\right)=0.0280 \\
\mathrm{~L}\left(F_{3}\right)=0.0280\end{array}$ & 0.1101 & 0.0065 \\
\hline Deng & $\begin{array}{l}\operatorname{Bel}\left(F_{1}\right)=0.7150 \\
\operatorname{Bel}\left(F_{2}\right)=0.2550 \\
\operatorname{Bel}\left(F_{3}\right)=0.0000\end{array}$ & $F_{1} / F_{1}$ & $\begin{array}{l}\mathrm{L}\left(F_{1}\right)=0.0070 \\
\mathrm{~L}\left(F_{2}\right)=0.0304 \\
\mathrm{~L}\left(F_{3}\right)=0.0304\end{array}$ & 0.4370 & 0.0070 \\
\hline Yager & $\begin{array}{l}\operatorname{Bel}\left(F_{1}\right)=0.0940 \\
\operatorname{Bel}\left(F_{2}\right)=0.1050 \\
\operatorname{Bel}\left(F_{3}\right)=0.0000\end{array}$ & Unknown $/ F_{1}$ & $\begin{array}{l}\mathrm{L}\left(F_{1}\right)=0.7940 \\
\mathrm{~L}\left(F_{2}\right)=0.8010 \\
\mathrm{~L}\left(F_{3}\right)=0.8010\end{array}$ & -0.7000 & 0.7940 \\
\hline Dubois & $\begin{array}{l}\operatorname{Bel}\left(F_{1}\right)=0.4580 \\
\operatorname{Bel}\left(F_{2}\right)=0.2055 \\
\operatorname{Bel}\left(F_{3}\right)=0.0000\end{array}$ & $F_{1} / F_{1}$ & $\begin{array}{l}\mathrm{L}\left(F_{1}\right)=0.3260 \\
\mathrm{~L}\left(F_{2}\right)=0.3365 \\
\mathrm{~L}\left(F_{3}\right)=0.0435\end{array}$ & 0.2225 & 0.0330 \\
\hline Smets & $\begin{array}{l}\operatorname{Bel}\left(F_{1}\right)=0.0940 \\
\operatorname{Bel}\left(F_{2}\right)=0.1050 \\
\operatorname{Bel}\left(F_{3}\right)=0.0000 \\
\operatorname{Bel} \varnothing)=0.7920\end{array}$ & Unknown $/ F_{1}$ & $\begin{array}{l}\mathrm{L}\left(F_{1}\right)=0.0020 \\
\mathrm{~L}\left(F_{2}\right)=0.0090 \\
\mathrm{~L}\left(F_{3}\right)=0.0090\end{array}$ & -0.6980 & 0.0000 \\
\hline Proposed method & $\begin{array}{l}\operatorname{Bel}\left(F_{1}\right)=0.5669 \\
\operatorname{Bel}\left(F_{2}\right)=0.3835 \\
\operatorname{Bel}\left(F_{3}\right)=0.0000\end{array}$ & $F_{1} / F_{1}$ & $\begin{array}{l}\mathrm{L}\left(F_{1}\right)=0.0147 \\
\mathrm{~L}\left(F_{2}\right)=0.0496 \\
\mathrm{~L}\left(F_{3}\right)=0.0496\end{array}$ & 0.1834 & 0.0147 \\
\hline
\end{tabular}

method is far greater than those obtained by Deng's method and the proposed method, which increases the uncertainty of identifying the object. Moreover, the unknown degree of the fusion result (0.0468) obtained by Dubois' method is greater than those obtained by Deng's method (0.0000) and the proposed method (0.0004). This indicates that the fusion ability of Dubois' method is relatively weak. Based on the indicators in Table 9, the fusion result of Deng's method is best, followed by that of the proposed method.

\subsubsection{Freeway incident detection based on multisource information fusion}

Case 3 There are usually two types of incident detection on the freeway, namely, A (incident state) and B (no incident state), which form a frame of discernment $\Theta$, denoted by $\Theta=\{A, B\}$. Three information sources are used to detect the incident state at the same location. The BPAs obtained based on the three information sources are as follows [51]:

Table 7 The BPA of the iris instance

\begin{tabular}{llllllll}
\hline Attributes & Se & Ve & Vi & Se, Ve & Se, Vi & Ve, Vi & $\Theta$ \\
\hline SL & 0.3337 & 0.3165 & 0.2816 & 0.0307 & 0.0052 & 0.0272 & 0.0052 \\
SW & 0.3164 & 0.2501 & 0.2732 & 0.0304 & 0.0481 & 0.0515 & 0.0304 \\
PL & 0.6699 & 0.2374 & 0.0884 & 0.0000 & 0.0000 & 0.0043 & 0.0000 \\
PW & 0.6996 & 0.2120 & 0.0658 & 0.0000 & 0.0000 & 0.0226 & 0.0000 \\
\hline
\end{tabular}

$\mathrm{S} 1: m_{1}(A)=0.4613 \quad m_{1}(B)=0.4750 \quad m_{1}(A, B)=0.0638$

$\mathrm{S} 2: m_{2}(A)=0.8606 \quad m_{2}(B)=0.0802 \quad m_{2}(A, B)=0.0593$

$\mathrm{S} 3: m_{3}(A)=0.1110 \quad m_{3}(B)=0.8594 \quad m_{3}(A, B)=0.0296$

As seen from these BPAs, S2 strongly supports the target to be A, while S3 strongly supports the target to be B, which indicates that there is a high conflict between S2 and S3. For $\mathrm{S} 1$, there is no significant difference between support for $\mathrm{A}$ and support for B, which shows that there is no significant conflict between evidence S1 and evidence S2 or S3. The results of various methods are shown in Table 10.

As seen from Table 10, D-S theory and Murphy's method obtain the wrong result. Bel(B) obtained by Yager's method, Dubois' method and Smets' method is too small to support the real target (B). Only the proposed method and Deng's method can yield the correct result, and there is no obvious difference between the fusion results of these two methods, which indicates that the two methods are better than the other methods. element $\Theta$. This causes the belief function of $\Theta$ to be much larger than that of any fault type, so it is unable to determine which fault is real. The proposed method is able to diagnose the fault type $F_{1}$, which is consistent with Murphy's method, Deng's method and Dubois' method, and the belief function of fault $F_{1}$ obtained by the proposed method is greater than that of Murphy's method and Dubois' method. Based on these four indicators, the performance of Deng's method is the best, followed by that of the proposed method. 
Table 8 The comparison of different methods applied in the Iris data set classification

\begin{tabular}{|c|c|c|c|c|c|}
\hline Methods & Belief function of the target to be identified & $\begin{array}{l}\text { Identified target } \\
\text { /real target }\end{array}$ & $\begin{array}{l}\text { Uncertainty interval } \\
\text { value }\end{array}$ & $\mathrm{D}$ value & The unknown degree \\
\hline D-S theory & $\begin{array}{l}\operatorname{Bel}(\mathrm{Se})=0.8947 \\
\operatorname{Bel}(\mathrm{Ve})=0.0927 \\
\operatorname{Bel}(\mathrm{Vi})=0.0126\end{array}$ & $\mathrm{Se} / \mathrm{Se}$ & $\begin{array}{l}\mathrm{L}(\mathrm{Se})=0.0000 \\
\mathrm{~L}(\mathrm{Ve})=0.0000 \\
\mathrm{~L}(\mathrm{Vi})=0.0000\end{array}$ & 0.8020 & 0.0000 \\
\hline Murphy & $\begin{array}{l}\operatorname{Bel}(\mathrm{Se})=0.8864 \\
\operatorname{Bel}(\mathrm{Ve})=0.0874 \\
\operatorname{Bel}(\mathrm{Vi})=0.0262\end{array}$ & $\mathrm{Se} / \mathrm{Se}$ & $\begin{array}{l}\mathrm{L}(\mathrm{Se})=0.0000 \\
\mathrm{~L}(\mathrm{Ve})=0.0000 \\
\mathrm{~L}(\mathrm{Vi})=0.0000\end{array}$ & 0.7990 & 0.0000 \\
\hline Deng & $\begin{array}{l}\operatorname{Bel}(\mathrm{Se})=0.8867 \\
\operatorname{Bel}(\mathrm{Ve})=0.0872 \\
\operatorname{Bel}(\mathrm{Vi})=0.0261\end{array}$ & $\mathrm{Se} / \mathrm{Se}$ & $\begin{array}{l}\mathrm{L}(\mathrm{Se})=0.0000 \\
\mathrm{~L}(\mathrm{Ve})=0.0000 \\
\mathrm{~L}(\mathrm{Vi})=0.0000\end{array}$ & 0.7995 & 0.0000 \\
\hline Yager & $\begin{array}{l}\operatorname{Bel}(\mathrm{Se})=0.0739 \\
\operatorname{Bel}(\mathrm{Ve})=0.0077 \\
\operatorname{Bel}(\mathrm{Vi})=0.0010\end{array}$ & Unknown/Se & $\begin{array}{l}\mathrm{L}(\mathrm{Se})=0.0000 \\
\mathrm{~L}(\mathrm{Ve})=0.0000 \\
\mathrm{~L}(\mathrm{Vi})=0.0000\end{array}$ & -0.8435 & 0.9174 \\
\hline Dubois & $\begin{array}{l}\operatorname{Bel}(\mathrm{Se})=0.5464 \\
\operatorname{Bel}(\mathrm{Ve})=0.1042 \\
\operatorname{Bel}(\mathrm{Vi})=0.0266\end{array}$ & $\mathrm{Se} / \mathrm{Se}$ & $\begin{array}{l}\mathrm{L}(\mathrm{Se})=0.2996 \\
\mathrm{~L}(\mathrm{Ve})=0.2638 \\
\mathrm{~L}(\mathrm{Vi})=0.1500\end{array}$ & 0.4422 & 0.0676 \\
\hline Smets & $\begin{array}{l}\operatorname{Bel}(\mathrm{Se})=0.0739 \\
\operatorname{Bel}(\mathrm{Ve})=0.0077 \\
\operatorname{Bel}(\mathrm{Vi})=0.0010 \\
\operatorname{Bel}(\varnothing)=0.9174\end{array}$ & Unknown/Se & $\begin{array}{l}\mathrm{L}(\mathrm{Se})=0.0000 \\
\mathrm{~L}(\mathrm{Ve})=0.0000 \\
\mathrm{~L}(\mathrm{Vi})=0.0000\end{array}$ & -0.8435 & 0.0000 \\
\hline Proposed method & $\begin{array}{l}\operatorname{Bel}(\mathrm{Se})=0.8947 \\
\operatorname{Bel}(\mathrm{Ve})=0.0927 \\
\operatorname{Bel}(\mathrm{Vi})=0.0126\end{array}$ & $\mathrm{Se} / \mathrm{Se}$ & $\begin{array}{l}\mathrm{L}(\mathrm{Se})=0.0000 \\
\mathrm{~L}(\mathrm{Ve})=0.0000 \\
\mathrm{~L}(\mathrm{Vi})=0.0000\end{array}$ & 0.8020 & 0.0000 \\
\hline
\end{tabular}

5.2.4 Emergency decision based on multisource information fusion

Case 4 There are usually conflicts in the emergency decision-making process of disaster accidents. In the process of fighting a chemical storage fire, five emergency experts gave different views on four emergency plans [52]. The four emergency rescue plans are $\mathrm{A}, \mathrm{B}, \mathrm{C}$, and $\mathrm{D}$, which form a frame of discernment $(\Theta)$, denoted by $\Theta=\{A, B, C, D\}$. The views from these emergency experts are turned into BPAs, which are listed below:

Table 9 The comparison of different methods applied in the Iris dataset classification under the disturbance condition

\begin{tabular}{|c|c|c|c|c|c|}
\hline Methods & $\begin{array}{l}\text { Belief function of the } \\
\text { target to be identified }\end{array}$ & $\begin{array}{l}\text { Identified target } \\
\text { /real target }\end{array}$ & $\begin{array}{l}\text { Uncertainty interval } \\
\text { value }\end{array}$ & $\mathrm{D}$ value & $\begin{array}{l}\text { The unknown } \\
\text { degree }\end{array}$ \\
\hline D-S theory & $\begin{array}{l}\operatorname{Bel}(\mathrm{Se})=0.0000 \\
\operatorname{Bel}(\mathrm{Ve})=0.9988 \\
\operatorname{Bel}(\mathrm{Vi})=0.0012\end{array}$ & $\mathrm{Ve} / \mathrm{Se}$ & $\begin{array}{l}\mathrm{L}(\mathrm{Se})=0.0000 \\
\mathrm{~L}(\mathrm{Ve})=0.0000 \\
\mathrm{~L}(\mathrm{Vi})=0.0000\end{array}$ & -0.9988 & 0.0000 \\
\hline Murphy & $\begin{array}{l}\operatorname{Bel}(\mathrm{Se})=0.4422 \\
\operatorname{Bel}(\mathrm{Ve})=0.5546 \\
\operatorname{Bel}(\mathrm{Vi})=0.0032\end{array}$ & $\mathrm{Ve} / \mathrm{Se}$ & $\begin{array}{l}\mathrm{L}(\mathrm{Se})=0.0000 \\
\mathrm{~L}(\mathrm{Ve})=0.0000 \\
\mathrm{~L}(\mathrm{Vi})=0.0000\end{array}$ & -0.1124 & 0.0000 \\
\hline Deng & $\begin{array}{l}\operatorname{Bel}(\mathrm{Se})=0.7300 \\
\operatorname{Bel}(\mathrm{Ve})=0.2652 \\
\operatorname{Bel}(\mathrm{Vi})=0.0047\end{array}$ & $\mathrm{Se} / \mathrm{Se}$ & $\begin{array}{l}\mathrm{L}(\mathrm{Se})=0.0000 \\
\mathrm{~L}(\mathrm{Ve})=0.0000 \\
\mathrm{~L}(\mathrm{Vi})=0.0000\end{array}$ & 0.4648 & 0.0000 \\
\hline Yager & $\begin{array}{l}\operatorname{Bel}(\mathrm{Se})=0.0000 \\
\operatorname{Bel}(\mathrm{Ve})=0.0213 \\
\operatorname{Bel}(\mathrm{Vi})=0.0000\end{array}$ & Unknown/Se & $\begin{array}{l}L(\mathrm{Se})=0.0000 \\
L(\mathrm{Ve})=0.0000 \\
L(\mathrm{Vi})=0.0000\end{array}$ & -0.9787 & 0.9787 \\
\hline Dubois & $\begin{array}{l}\operatorname{Bel}(\mathrm{Se})=0.4897 \\
\operatorname{Bel}(\mathrm{Ve})=0.1690 \\
\operatorname{Bel}(\mathrm{Vi})=0.0192\end{array}$ & $\mathrm{Se} / \mathrm{Se}$ & $\begin{array}{l}\mathrm{L}(\mathrm{Se})=0.2952 \\
\mathrm{~L}(\mathrm{Ve})=0.2891 \\
\mathrm{~L}(\mathrm{Vi})=0.1069\end{array}$ & 0.3207 & 0.0468 \\
\hline Smets & $\begin{array}{l}\operatorname{Bel}(\mathrm{Se})=0.0000 \\
\operatorname{Bel}(\mathrm{Ve})=0.0213 \\
\operatorname{Bel}(\mathrm{Vi})=0.0000 \\
\operatorname{Bel}(\varnothing)=0.9787\end{array}$ & Unknown/Se & $\begin{array}{l}\mathrm{L}(\mathrm{Se})=0.0000 \\
\mathrm{~L}(\mathrm{Ve})=0.0000 \\
\mathrm{~L}(\mathrm{Vi})=0.0000\end{array}$ & -0.9787 & 0.0000 \\
\hline Proposed method & $\begin{array}{l}\operatorname{Bel}(\mathrm{Se})=0.5436 \\
\operatorname{Bel}(\mathrm{Ve})=0.4388 \\
\operatorname{Bel}(\mathrm{Vi})=0.0166\end{array}$ & $\mathrm{Se} / \mathrm{Se}$ & $\begin{array}{l}\mathrm{L}(\mathrm{Se})=0.0006 \\
\mathrm{~L}(\mathrm{Ve})=0.0010 \\
\mathrm{~L}(\mathrm{Vi})=0.0008\end{array}$ & 0.1048 & 0.0004 \\
\hline
\end{tabular}


Table 10 Comparison of different methods applied in incident detection

\begin{tabular}{|c|c|c|c|c|c|}
\hline Methods & $\begin{array}{l}\text { Belief function of the } \\
\text { target to be identified }\end{array}$ & $\begin{array}{l}\text { Identified target/real } \\
\text { target }\end{array}$ & $\begin{array}{l}\text { Uncertainty interval } \\
\text { value }\end{array}$ & $\mathrm{D}$ value & $\begin{array}{l}\text { The unknown } \\
\text { degree }\end{array}$ \\
\hline \multirow[t]{2}{*}{ D-S theory } & $\operatorname{Bel}(\mathrm{A})=0.5038$ & \multirow[t]{2}{*}{$\mathrm{A} / \mathrm{B}$} & $\mathrm{L}(\mathrm{A})=0.0008$ & \multirow[t]{2}{*}{0.0084} & \multirow[t]{2}{*}{0.0008} \\
\hline & $\operatorname{Bel}(B)=0.4954$ & & $\mathrm{~L}(\mathrm{~B})=0.0008$ & & \\
\hline \multirow[t]{2}{*}{ Murphy } & $\operatorname{Bel}(\mathrm{A})=0.5085$ & \multirow[t]{2}{*}{$\mathrm{A} / \mathrm{B}$} & $\mathrm{L}(\mathrm{A})=0.0000$ & \multirow[t]{2}{*}{0.0174} & \multirow[t]{2}{*}{0.0005} \\
\hline & $\operatorname{Bel}(\mathrm{B})=0.4911$ & & $\mathrm{~L}(\mathrm{~B})=0.0000$ & & \\
\hline \multirow[t]{2}{*}{ Deng } & $\operatorname{Bel}(\mathrm{A})=0.4939$ & \multirow[t]{2}{*}{$\mathrm{B} / \mathrm{B}$} & $\mathrm{L}(\mathrm{A})=0.0005$ & \multirow[t]{2}{*}{0.0117} & \multirow[t]{2}{*}{0.0005} \\
\hline & $\operatorname{Bel}(\mathrm{B})=0.5056$ & & $\mathrm{~L}(\mathrm{~B})=0.0005$ & & \\
\hline \multirow[t]{2}{*}{ Yager } & $\operatorname{Bel}(\mathrm{A})=0.0678$ & \multirow[t]{2}{*}{ Unknown/B } & $L(A)=0.8656$ & \multirow[t]{2}{*}{0.0011} & \multirow[t]{2}{*}{0.8656} \\
\hline & $\operatorname{Bel}(\mathrm{B})=0.0667$ & & $\mathrm{~L}(\mathrm{~B})=0.8656$ & & \\
\hline \multirow[t]{2}{*}{ Dubois } & $\operatorname{Bel}(\mathrm{A})=0.0678$ & \multirow[t]{2}{*}{ Unknown/B } & $L(A)=0.8656$ & \multirow[t]{2}{*}{0.0011} & \multirow[t]{2}{*}{0.8656} \\
\hline & $\operatorname{Bel}(\mathrm{B})=0.0667$ & & $\mathrm{~L}(\mathrm{~B})=0.8656$ & & \\
\hline \multirow[t]{3}{*}{ Smets } & $\operatorname{Bel}(\mathrm{A})=0.0678$ & \multirow[t]{3}{*}{ Unknown/B } & $\mathrm{L}(\mathrm{A})=0.0001$ & \multirow[t]{3}{*}{-0.7987} & \multirow[t]{3}{*}{0.0001} \\
\hline & $\operatorname{Bel}(\mathrm{B})=0.0667$ & & $\mathrm{~L}(\mathrm{~B})=0.0001$ & & \\
\hline & $\operatorname{Bel}(\varnothing)=0.8654$ & & & & \\
\hline \multirow[t]{2}{*}{ Proposed method } & $\operatorname{Bel}(\mathrm{A})=0.4871$ & \multirow[t]{2}{*}{$\mathrm{B} / \mathrm{B}$} & $\mathrm{L}(\mathrm{A})=0.0070$ & \multirow[t]{2}{*}{0.0187} & \multirow[t]{2}{*}{0.0070} \\
\hline & $\operatorname{Bel}(\mathrm{B})=0.5058$ & & $\mathrm{~L}(\mathrm{~B})=0.0070$ & & \\
\hline
\end{tabular}

$$
\begin{aligned}
\mathrm{E}_{1}: m_{1}(A)=0.3333 & m_{1}(B)=0.3750 \\
m_{1}(C)=0.1667 & m_{1}(D)=0.1250 \\
\mathrm{E}_{2}: m_{2}(A)=0.3103 & m_{2}(B)=0.2069 \\
m_{2}(C)=0.2759 & m_{2}(D)=0.2069
\end{aligned}
$$

\begin{tabular}{|c|c|c|c|c|c|}
\hline Methods & $\begin{array}{l}\text { Belief function of the } \\
\text { target to be identified }\end{array}$ & $\begin{array}{l}\text { Identified target } \\
\text { /real target }\end{array}$ & $\begin{array}{l}\text { Uncertainty interval } \\
\text { value }\end{array}$ & $\mathrm{D}$ value & $\begin{array}{l}\text { The unknown } \\
\text { degree }\end{array}$ \\
\hline \multirow[t]{4}{*}{ D-S theory } & $\operatorname{Bel}(\mathrm{A})=0.3160$ & \multirow[t]{4}{*}{$\mathrm{A} / \mathrm{B}$} & $\mathrm{L}(\mathrm{A})=0.0000$ & \multirow[t]{4}{*}{-0.0209} & \multirow[t]{4}{*}{0.0000} \\
\hline & $\operatorname{Bel}(\mathrm{B})=0.2951$ & & $\mathrm{~L}(\mathrm{~B})=0.0000$ & & \\
\hline & $\operatorname{Bel}(\mathrm{C})=0.2625$ & & $\mathrm{~L}(\mathrm{C})=0.0000$ & & \\
\hline & $\operatorname{Bel}(\mathrm{D})=0.1265$ & & $\mathrm{~L}(\mathrm{D})=0.0000$ & & \\
\hline \multirow[t]{4}{*}{ Murphy } & $\operatorname{Bel}(\mathrm{A})=0.3237$ & \multirow[t]{4}{*}{$\mathrm{A} / \mathrm{B}$} & $\mathrm{L}(\mathrm{A})=0.0000$ & \multirow[t]{4}{*}{-0.0333} & \multirow[t]{4}{*}{0.0000} \\
\hline & $\operatorname{Bel}(\mathrm{B})=0.2904$ & & $\mathrm{~L}(\mathrm{~B})=0.0000$ & & \\
\hline & $\operatorname{Bel}(\mathrm{C})=0.2494$ & & $\mathrm{~L}(\mathrm{C})=0.0000$ & & \\
\hline & $\operatorname{Bel}(\mathrm{D})=0.1366$ & & $\mathrm{~L}(\mathrm{D})=0.0000$ & & \\
\hline \multirow[t]{4}{*}{ Deng } & $\operatorname{Bel}(\mathrm{A})=0.3208$ & \multirow[t]{4}{*}{$\mathrm{A} / \mathrm{B}$} & $\mathrm{L}(\mathrm{A})=0.0000$ & \multirow[t]{4}{*}{-0.0407} & \multirow[t]{4}{*}{0.0000} \\
\hline & $\operatorname{Bel}(\mathrm{B})=0.2804$ & & $\mathrm{~L}(\mathrm{~B})=0.0000$ & & \\
\hline & $\operatorname{Bel}(\mathrm{C})=0.2575$ & & $\mathrm{~L}(\mathrm{C})=0.0000$ & & \\
\hline & $\operatorname{Bel}(\mathrm{D})=0.1413$ & & $\mathrm{~L}(\mathrm{D})=0.0000$ & & \\
\hline \multirow[t]{4}{*}{ Yager } & $\operatorname{Bel}(\mathrm{A})=0.0011$ & \multirow[t]{4}{*}{ Unknown/B } & $L(A)=0.9965$ & \multirow[t]{4}{*}{-0.9955} & \multirow[t]{4}{*}{0.9965} \\
\hline & $\operatorname{Bel}(\mathrm{B})=0.0010$ & & $\mathrm{~L}(\mathrm{~B})=0.9965$ & & \\
\hline & $\operatorname{Bel}(\mathrm{C})=0.0009$ & & $\mathrm{~L}(\mathrm{C})=0.9965$ & & \\
\hline & $\operatorname{Bel}(\mathrm{D})=0.0004$ & & $\mathrm{~L}(\mathrm{D})=0.9965$ & & \\
\hline \multirow[t]{4}{*}{ Dubois } & $\operatorname{Bel}(\mathrm{A})=0.0868$ & \multirow[t]{4}{*}{ Unknown/B } & $\mathrm{L}(\mathrm{A})=0.3108$ & \multirow[t]{4}{*}{-0.0068} & \multirow[t]{4}{*}{0.0245} \\
\hline & $\operatorname{Bel}(\mathrm{B})=0.1174$ & & $\mathrm{~L}(\mathrm{~B})=0.3327$ & & \\
\hline & $\operatorname{Bel}(\mathrm{C})=0.1226$ & & $\mathrm{~L}(\mathrm{C})=0.3406$ & & \\
\hline & $\operatorname{Bel}(\mathrm{D})=0.1242$ & & $L(D)=0.3346$ & & \\
\hline \multirow[t]{5}{*}{ Smets } & $\operatorname{Bel}(\mathrm{A})=0.0011$ & \multirow[t]{5}{*}{ Unknown/B } & $\mathrm{L}(\mathrm{A})=0.0000$ & \multirow[t]{5}{*}{-0.9955} & \multirow[t]{5}{*}{0.0001} \\
\hline & $\operatorname{Bel}(\mathrm{B})=0.0010$ & & $\mathrm{~L}(\mathrm{~B})=0.0000$ & & \\
\hline & $\operatorname{Bel}(\mathrm{C})=0.0009$ & & $\mathrm{~L}(\mathrm{C})=0.0000$ & & \\
\hline & $\operatorname{Bel}(\mathrm{D})=0.0004$ & & $L(D)=0.0000$ & & \\
\hline & $\operatorname{Bel}(\varnothing)=0.9965$ & & & & \\
\hline \multirow[t]{4}{*}{ Proposed method } & $\operatorname{Bel}(\mathrm{A})=0.2991$ & \multirow[t]{4}{*}{$\mathrm{B} / \mathrm{B}$} & $\mathrm{L}(\mathrm{A})=0.0000$ & \multirow[t]{4}{*}{0.0198} & \multirow[t]{4}{*}{0.0000} \\
\hline & $\operatorname{Bel}(\mathrm{B})=0.3189$ & & $\mathrm{~L}(\mathrm{~B})=0.0000$ & & \\
\hline & $\operatorname{Bel}(\mathrm{C})=0.2442$ & & $\mathrm{~L}(\mathrm{C})=0.0000$ & & \\
\hline & $\operatorname{Bel}(\mathrm{D})=0.1378$ & & $\mathrm{~L}(\mathrm{D})=0.0000$ & & \\
\hline
\end{tabular}

$$
\begin{aligned}
\mathrm{E}_{3}: m_{3}(A)=0.3103 & m_{3}(B)=0.2069 \\
m_{3}(C)=0.2759 & m_{3}(D)=0.2069 \\
\mathrm{E}_{4}: m_{4}(A)=0.1875 & m_{4}(B)=0.2500 \\
m_{4}(C)=0.2813 & m_{4}(D)=0.2813
\end{aligned}
$$

Table 11 The comparison of different methods applied in emergency decisions 


$$
\begin{aligned}
\mathrm{E}_{5}: m_{5}(A)=0.1852 & m_{5}(B)=0.2593 \\
m_{5}(C)=0.2593 & m_{5}(D)=0.2963
\end{aligned}
$$

$\mathrm{E}_{i}(i=1,2, \cdots 5)$ represents the view of the $i$ th expert. Based on the data above, these experts have different views on the four emergency rescue plans. Emergency expert 1 supports rescue plan B. Expert 2 and expert 3 are in favour of plan A. Expert 4 prefers plan C and D. Expert 5 supports plan D. The fusion results of different views by different methods are shown in Table 11.

From Table 11, the rescue plan A should be the best execution plan based on the fusion results obtained by D-S theory, Murphy's method and Deng's method. However, it is an incorrect conclusion according to reference [52]. Yager's method, Dubois method and Smets' method lose the polarizability of Dempster's rule of combination, which leads to the belief function of each plan after multiple information fusion being too small to provide any useful information for identifying the optimal rescue plan. Only the proposed method can select the optimal plan. The case shows that the proposed method is superior to the other methods.

\section{Discussion}

Through the study of examples and real cases, the performance of various fusion methods was discussed.

(1) Which of the three approaches of improved D-S theory is best?

Given the closed-world assumption, that is, the frame of discernment contains all possible research propositions, the belief function of each proposition obtained by the combination rule proposed by Smets based on the open-world assumption is too small to identify the real target. The fusion results of the above examples show that the method cannot provide effective information for identifying the real target.

Yager's method and Dubois' method are typical representatives of modified versions of Dempster's rule of combination. However, Yager's method cannot identify the real target in all examples and cases except for example 3 in Fig. 7. Although Dubois' method identifies the correct result in some examples, it cannot identify the real target in all cases. Moreover, the uncertain interval value and the unknown degree obtained by these two methods are larger than those obtained by other methods, and the $\mathrm{D}$ value is relatively small.

Murphy's method and Deng's method belong to the weighted fusion method for modifying sources of evidence. The difference between the two is that Murphy does not consider the difference in the weight of the evidence, while Deng takes into account the difference in the weight of the evidence. According to the fusion results of the examples in section 5.1, the performances of Murphy's method and Deng's method are better than those of Yager's method, Dubois' method and Smets' method. However, the two methods do not produce the right results when fusing different amounts of evidence in certain examples, for example, Deng's method fails to identify the real target in example 6 in Fig. 9, and Murphy's method fails to identify the real target in example 4 in Fig. 8. Based on the fusion results of the cases in section 5.2, Murphy's method cannot identify the real target in cases 3,4 , or 2 which is under the disturbance condition, and Deng's method cannot identify the real target in case 4.

Based on the above analysis, although Murphy's method and Deng's method cannot obtain the correct results in some cases in the paper, the two methods outperform Yager's method, Dubois' method and Smets' method in terms of various indicators of the fusion results. Therefore, the approach of modifying evidence sources is better than the other two approaches.

(2) How does the proposed method compare with Deng's method and Murphy's method?

Murphy's method replaces multiple original bodies of evidence with the average evidence. In many situations, reasonable fusion results can be obtained, but when there is extremely abnormal evidence, multiple valid bodies of evidence are needed to offset the adverse effects of abnormal evidence. If the amount of valid evidence is limited, then this method will yield the wrong fusion results, as shown in Table 9, in case 3 and case 4. Deng's method takes into account the weight of the evidence and makes up for Murphy's shortcomings. However, this method excessively excludes abnormal information, which easily causes the loss of weak information. It may fail to identify the correct results, such as in case 4 and example 6 in Fig. 9. Moreover, because the weighted evidence itself fuses, the operation lacks reasonable explanation and undermines the independence of the evidence for Deng's and Murphy's method. The proposed method avoids the defects of these two methods by redistributing BPAs, which is efficient in dealing with conflicting evidence under various circumstances. Based on the fusion results in section 5 , it can be seen that the ability of the proposed method to identify real targets is better than Deng's method and Murphy's method, which indicates that the proposed method has the widest range of applications.

\section{(3) Limitations of the proposed method}

The proposed method deals with conflicting evidence to determine the target to be identified based on the closedworld frame of discernment. If the target to be identified is not within the closed frame, the proposed method cannot obtain the correct result. Determining how the proposed method can 
be improved to obtain the correct results in an open frame of discernment is a promising direction for future work. In addition, it is difficult to determine the adjusted coefficient $(\alpha)$ in Eq. (16). The paper gives only three reference values $(0,0.5,1)$, but alpha can not only take any value between 0 and 1 but also take a value greater than 1 . If the value of alpha is reasonable, the correct results can be obtained in examples 1, 2 and 4 when two pieces of evidence are fused. How the value range of alpha and the value of alpha corresponding to each piece of evidence can be determine has not been studied in detail. Future research should investigate the value of alpha to optimize the proposed method.

\section{Conclusions}

To solve the paradoxical problem of multisource information fusion, an improved combination method for conflicting evi- dence based on the redistribution of the BPA is proposed. By modifying the original BPAs twice, the conflict between the evidence is reduced. The proposed method not only retains the mathematical properties of D-S theory but also overcomes the disadvantages of the weighted average and the discounting method. The examples show that the proposed method is effective and feasible in dealing with the problem of the fusion of evidence in different conflicts, which is not limited to addressing the fusion of high-conflict evidence but is also applicable to the fusion of conflicting evidence in general. In addition, four actual cases are presented to demonstrate that the proposed method is able to deal with cases that cannot be solved by other methods, which expands the application of D-S theory.

In future work, we focus on how the proposed method can be improved to obtain the correct results in an open frame of discernment. In addition, how the value range of alpha and the value of alpha corresponding to each piece of evidence can be determined needs to be researched in detail.

\section{Appendix}

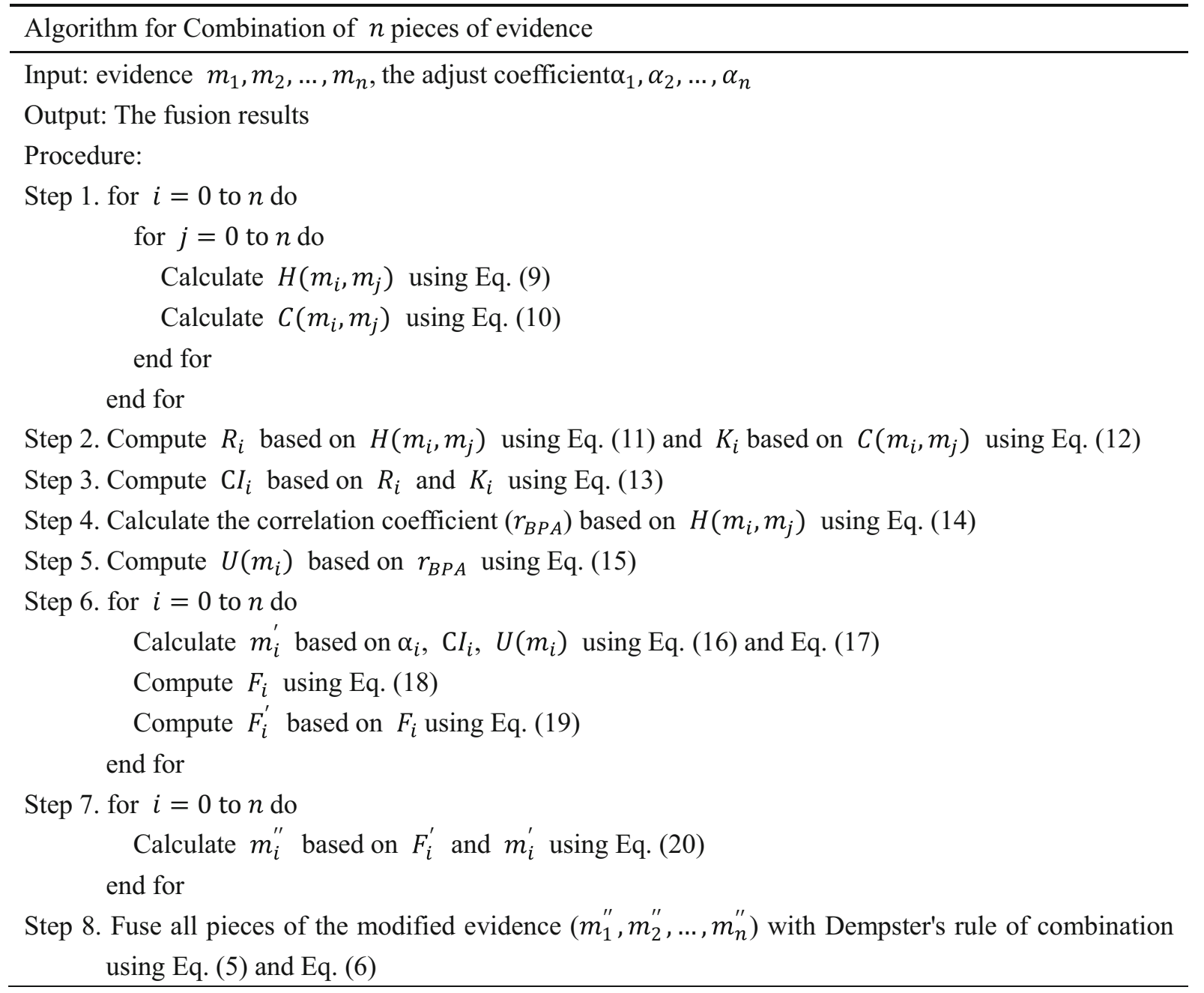


Acknowledgments This project was supported by the National Key Research and Development Program of China 2017YFB0504102 and 2017YFC1502902.

Open Access This article is licensed under a Creative Commons Attribution 4.0 International License, which permits use, sharing, adaptation, distribution and reproduction in any medium or format, as long as you give appropriate credit to the original author(s) and the source, provide a link to the Creative Commons licence, and indicate if changes were made. The images or other third party material in this article are included in the article's Creative Commons licence, unless indicated otherwise in a credit line to the material. If material is not included in the article's Creative Commons licence and your intended use is not permitted by statutory regulation or exceeds the permitted use, you will need to obtain permission directly from the copyright holder. To view a copy of this licence, visit http://creativecommons.org/licenses/by/4.0/.

\section{References}

1. Jiang W, Wang S, Liu X, Zheng H, Wei B (2017) Evidence conflict measure based on OWA operator in open world. Plos One 12(5): e0177828. https://doi.org/10.1371/journal.pone.0177828

2. Silva LGDO, Almeida-Filho ATD (2018) A new PROMETHEEbased approach applied within a framework for conflict analysis in evidence theory integrating three conflict measures. Expert Syst Appl 113:223-232

3. Xiao F (2019) Multi-sensor data fusion based on the belief divergence measure of evidences and the belief entropy. Inf Fusion 46: 23-32

4. Sarabi-Jamab A, Araabi BN (2018) How to decide when the sources of evidence are unreliable: a multi-criteria discounting approach in the Dempster-Shafer theory. Inf Sci 448:233-248

5. Zhao Y, Jia R, Shi P (2016) A novel combination method for conflicting evidence based on inconsistent measurements. Inf Sci 367:125-142

6. Jiang W, Cao Y, Yang L, He Z (2017) A time-space domain information fusion method for specific emitter identification based on Dempster-Shafer evidence theory. Sensors 17(9). https://doi.org/ 10.3390/s17091972

7. Vandecasteele F, Merci B, Verstockt S (2016) Reasoning on multisensor geographic smoke spread data for firedevelopment and risk analysis. Fire Saf J 86:65-74

8. Jiang W, Xie C, Wei B, Zhou D (2016) A modified method for risk evaluation in failure modes and effects analysis of aircraft turbine rotor blades. Adv Mech Eng 8(4):1-16

9. Su X, Mahadevan S, Xu P, Deng Y (2015) Dependence assessment in human reliability analysis using evidence theory and AHP. Risk Anal 35(7):1296

10. Wang J, Hu Y, Xiao F, Deng X, Deng Y (2016) A novel method to use fuzzy soft sets in decision making based on ambiguity measure and Dempster-Shafer theory of evidence: An application in medical diagnosis. Artif Intell. Med 69:1-11

11. Lian C, Ruan S, Denoeux T (2015) An evidential classifier based on feature selection and two-step classification strategy. Pattern Recogn 48(7):2318-2327

12. Hang J, Zhang J, Cheng M (2014) Fault diagnosis of wind turbine based on multi-sensors information fusion technology. IET Renew Power Gener 8(3):289-298
13. Geng H, Liang Y, Yang F, Xu L, Pan Q (2017) Model-reduced fault detection for multi-rate sensor fusion with unknown inputs. Inf Fusion 33:1-14

14. Islam MS, Sadiq R, Rodriguez MJ, Najjaran H, Hoorfar M (2016) Integrated decision support system for prognostic and diagnostic analyses of water distribution system failures. Water Resour Manag 30:2831-2850

15. Ma J, Liu W, Miller P, Zhou H (2016) An evidential fusion approach for gender profiling. Inf Sci 333:10-20

16. Liu Z-g, Pan Q, Dezert J, Martin A (2016) Adaptive imputation of missing values for incomplete pattern classification. Patt Recognit 52:85-95

17. Zadeh LA (1986) A simple view of the Dempster-Shafer theory of evidence and its implication for the rule of combination. AI Mag. 7(2):85-90

18. Jiang W (2018) A correlation coefficient for belief functions. Int J Approx Reason 103:94-106

19. Moenks U, Doerksen H, Lohweg V, Huebner M (2016) Information fusion of conflicting input data. Sensors 16(11):1798

20. Qian J, Guo X, Deng Y (2017) A novel method for combining conflicting evidences based on information entropy. Appl Intell 46:876-888

21. Xiao F, Qin B (2018) A Weighted Combination Method for Conflicting Evidence in Multi-Sensor Data Fusion. Sensors 18(5). https://doi.org/10.3390/s18051487

22. Silva LGDO, Almeida-Filho ATD (2016) A multicriteria approach for analysis of conflicts in evidence theory. Inf Sci 346:275-285

23. Jiang W, Deng X (2018) Information modeling and application of D-S evidence theory. Science press, Beijing

24. Yager R (1987) On the Dempster-Shafer framework and new combination rules. Inf Sci 41:93-137

25. Dubois D, Prade H (1988) Representation and combination of uncertainty with belief functions and possibility measures. Comput Intell 4(3):244-264

26. Lefevre E, Colot O, Vannoorenberghe $\mathrm{P}$ (2002) Belief function combination and conflict management. Inf. Fusion 3(2):149-162

27. Daniel M (2003) Associativity in combination of belief functions: a derivation of minC combination. Soft Comput 7(5):288-296

28. Yu C, Yang J, Yang D, Ma X, Min H (2015) An improved conflicting evidence combination approach based on a new supporting probability distance. Expert Syst Appl 42:5139-5149

29. Murphy CK (2000) Combining belief functions when evidence conflicts. Decis Support Syst 29(1):1-9

30. Deng Y, Shi W-K, Zhu Z-F (2004) Efficient combination approach of conflict evidence. J Infrared Millim Waves 23(1):27-32

31. Li J, Xie XB, Jin Y, Hu Z, Lin Z (2020) Weighted Conflict Evidence Combination Method Based on Hellinger Distance and the Belief Entropy. IEEE Access 8:225507-225521

32. Wang J, Qiao K, Zhang Z (2019) An improvement for combination rule in evidence theory. Futur Gener Comput Syst 91:1-9

33. Yuan K, Xiao F, Fei L, Kang B, Deng Y (2016) Conflict management based on belief function entropy in sensor fusion. Springerplus 5(1):638

34. Shafer G (1976) A mathematical theory of evidence, Princeton University Press

35. Yang Y, Han D, Han C (2013) Discounted combination of unreliable evidence using degree of disagreement. Int J Approx Reason 54:1197-1216

36. Schubert J (2011) Conflict management in Dempster-Shafer theory using the degree of falsity. Int J Approx Reason 52:449-460

37. Zhang J, Deng Y (2017) A method to determine basic probability assignment in the open world and its application in data fusion and classification. Appl Intell 46:934-951

38. Smets P (1990) The combination of evidence in the transferable belief model. IEEE Trans Pattern Anal Mach Intell 12(5):447-458 
39. Tang Y, Zhou D, Chan FT (2018) An extension to Deng's entropy in the open world assumption with an application in sensor data fusion. Sensors 18(6). https://doi.org/10.3390/s18061902

40. Sun R, Deng Y (2019) A new method to determine generalized basic probability assignment in the open world. IEEE Access 7: 52827-52835

41. Zhang X, Mu L-H (2016) Evidence combination rule based on local conflict elimination. Syst Eng Electron 38(7):1594-1599

42. Zhang Y, Liu Y, Zeng Q-A, Liu Q (2018) An Integrated Data Combination Method in Wireless Sensor Networks. Int J Interdiscip Telecommun Netw 10(4):61-76

43. Wang X, Song Y, Shi C (2018) Uncertain information representation and fusion. Science press, Beijing

44. Zhang L, Wu X, Zhu H, AbouRizk SM (2017) Perceiving safety risk of buildings adjacent to tunneling excavation: an information fusion approach. Autom Constr 73:88-101

45. Ye F, Chen J, Tian Y (2018) A robust DS combination method based on evidence correction and conflict redistribution, J Sens DOI https://doi.org/10.1155/2018/6526018

46. Yang F, Wang X (2010) Combination method of conflictive evidences in D-S evidence theory. National Defense Industry Press, Beijing
47. Jiang W, Deng X (2018) Information modeling and application of D-S evidence theory. Science press, Beijing

48. Zhang W, Ji X, Yang Y, Chen J, Gao Z, Qiu X (2018) Data Fusion Method Based on Improved D-S Evidence Theory, IEEE International Conference on Big Data and Smart Computing (BigComp), Shanghai

49. Frikha A, Moalla H (2015) Analytic hierarchy process for multisensor data fusion based on belief function theory. Eur J Operation Res 241:133-147

50. Chen Y-X, Luo C-K, Wang P, Cai Z-Y, Li C (2018) Combination of temporal evidence by considering reliability. Control Decision 33(3):463-470

51. Qin P, Yuan D, Ming D (2007) Multi-information fusion based on D-S evidence reasoning for freeway incident detection. Transducer Microsyst Technol 26(4):24-27

52. Xia D, Gao P, Ren S, Zhu H, Zhang Y (2019) Conflict coordination model for emergency decision making in disaster accidents. China Safety Sci J 29(3):174-179

Publisher's note Springer Nature remains neutral with regard to jurisdictional claims in published maps and institutional affiliations. 